\title{
A review on the application of iron(III) fluorides as positive electrodes for secondary cells
}

\author{
Donato E. Conte $\cdot$ Nicola Pinna
}

Received: 3 June 2014/ Accepted: 21 August 2014/Published online: 24 September 2014

(C) The Author(s) 2014. This article is published with open access at Springerlink.com

\begin{abstract}
Among the many industrial and research level applications of fluorides like microelectronics, polymers, agronomy, imaging, dental composites, uranium enrichment processes or catalysis, there is a recent and growing interest for these ionic compounds in the field of energy storage and conversion. Li-ion technology in particular, has been attracted to fluorides due to the possibility of morethan-one electrode reaction. In fact, these reactions can potentially enhance the energy stored in commercial cells (conversion reactions). By reaction with lithium, transition metal fluorides such as $\mathrm{MnF}_{3}, \mathrm{FeF}_{3}, \mathrm{CoF}_{3}$ or $\mathrm{CuF}_{2}$, can be reduced to the respective zero valent metal/LiF mixture with resulting high theoretical capacities ranging from 3 to 4.2 times the amount currently delivered by commercial $\mathrm{LiFePO}_{4}\left(170 \mathrm{mAh} \mathrm{g}^{-1}\right)$. Since, in practice, the most of the research efforts are being put into iron trifluoride due to chemical (relatively mild synthesis conditions), electrochemical (lower polarization than $\mathrm{MnF}_{3}$ for example) and environmental ( $\mathrm{Fe}$ is more environmentally friendly than Co) reasons, in this review we will focus on the electrochemistry, synthesis strategies and amelioration techniques for the high oxidation state ferric fluoride and its derivatives.
\end{abstract}

Keywords Iron fluoride $\cdot \mathrm{Li}$-ion $\cdot$ Batteries

D. E. Conte $(\bowtie) \cdot$ N. Pinna

Institut für Chemie, Humboldt-Universität zu Berlin,

Brook-Taylor-Str. 2, 12489 Berlin, Germany

e-mail: donato.e.conte@gmail.com

\section{Introduction}

Metal fluorides are ionic compounds that have been known since the late Renaissance era when they were used to render aluminum slags less viscous during the smelting process $\left(\mathrm{CaF}_{2}\right.$ fluxes) [1]. More recent applications, both at the industrial and research levels include: etching of silicon wafers for microelectronics, production of fluorinated polymers, agronomic compounds, medical imaging products and dental composites for caries control, uranium enrichment processes, catalysis and energy storage and conversion [2-4].

In the latter field, in particular, fluorides have attracted attention due to the conversion reaction with lithium ions. In conversion reactions, the transition-metal, $\mathrm{M}$, of an initial MX species ( $\mathrm{X}=\mathrm{H}, \mathrm{N}, \mathrm{O}, \mathrm{F}, \mathrm{P}$ or $\mathrm{S}$ ) is reduced by lithium to give $\mathrm{LiX}$ and the pure metal [5]. Since the first report of such kind of reaction in oxides [6], it has been clear that the involved materials could greatly enhance the energy stored in Li-ion cells. The reason for such high energy densities lies in the possibility for the transition metal to pass through various oxidation states involving more than one electron. For example, put aside the reaction potential, $\mathrm{FeF}_{3}$ would reach $712 \mathrm{mAh} \mathrm{g}^{-1}$ for its complete 3 electron reaction, while in $\mathrm{LiFePO}_{4}$ only the $\mathrm{Fe}(\mathrm{III}) / \mathrm{Fe}(\mathrm{II})$ couple will be active, delivering a theoretical maximum of $170 \mathrm{mAh} \mathrm{g}^{-1}$ (4.2 times less than iron trifluoride).

Recently, more and more research targets the optimization of high energy anode materials ( $\mathrm{Si}, \mathrm{Sn}$, oxides, etc.) [7]. Some prototypes could be brought to the market in the near future. However, at the current state of research, cathodes still represent the main cell limitation [8]. In fact it is not possible to assemble a performing full cell using a high energy anode if the cathode material cannot match that energy. Considering a cell that would be assembled 
with a $\mathrm{Si}$ anode, a high amount of lithium can theoretically react delivering around $4,000 \mathrm{mAh} \mathrm{g}^{-1}\left(\mathrm{Si}+4.4 \mathrm{Li}^{+}+\right.$ $\left.4.4 \mathrm{e}^{-} \rightarrow \mathrm{Li}_{4.4} \mathrm{Si}\right)$. If, in a purely speculative way, this high capacity can be reached and sustained for several hundreds of cycles, such an achievement would be completely useless when the coupling would be done with $\mathrm{LiFePO}_{4}$-based cathodes for example. In fact since in full $\mathrm{Li}$-ion cells, cathodes constitute the $\mathrm{Li}^{+}$reservoir (this is the reason why new portable gadgets have to be charged during the very first use), the $170 \mathrm{mAh} \mathrm{g}^{-1}$ of $1 \mathrm{~g}$ of $\mathrm{LiFePO}_{4}$ will never be enough for the full reaction of $\mathrm{Si}$. This leaves the manufacturer with two options: assemble the commercial cell with a Si-based anode without using its full energy potential or balance the amount of cathode using 4.4 times more of cathodic powder than anodic one. Such an increase in the amount of active material has both an economic and an engineering impact on the final cells. For these reasons, the development of cathode materials exhibiting reversible, more-than-one electron reactions would constitute one of the major breakthroughs for the realization of the next generation of accumulators, some other requirements being high voltage reactions and flat reaction plateaus.

In this review, we will focus mainly on the electrochemical reaction and synthesis strategies for the high oxidation state ferric fluoride and its derivatives as cathodes for the next generation of electrochemical accumulators.

\section{Early research, characteristics and electrochemical mechanism of $\mathrm{FeF}_{3}$}

Fluoride-based cathodes have been investigated very early during the development of Li-based cells. Already in the 1960s, Lockheed investigated $\mathrm{CuF}_{2}$ and $\mathrm{CoF}_{3}$ to develop long-lasting Li-based primary cells for use in space applications [9-11]. Later, in the 1970s, $\mathrm{AgF}_{2}, \mathrm{NiF}_{2}$ and $\mathrm{BiF}_{3}$ were also investigated for primary cells [12]. The first prototypes of the modern Li-ion cells were developed following the proposal (around 1980 [13]) and commercial application (in 1990 [14]) of the "rocking chair" systems, effectively clarifying that research in cathode materials would be a prominent field for the following years.

The first investigation of $\mathrm{FeF}_{3}$ was made by Arai et al. in a study published in 1997 [15]. The study was performed on a commercially available product in the region $4.5-2 \mathrm{~V}$ versus $\mathrm{Li}^{+} / \mathrm{Li}$. The authors identified the topotactic insertion reaction during the first part of the discharge with a maximum reaction of $0.5 \mathrm{Li}^{+}$. This behavior accounts for half of the currently demonstrated insertion of $1 \mathrm{Li}^{+}$per formula unit. The most probable reason is the lack of nanostructuration of the commercial $\mathrm{FeF}_{3}$.
After the above-mentioned study, fluoride-based cathodes were somehow left aside for some years to the profit of more immediately interesting compounds like oxides or phosphates. The reason for this slowing down of the research lies in the intrinsic, poor electronic conductivity of the fluoride which is due to the large bandgap induced by the highly ionic character of the metal-halogen bond. Badway et al. [16, 17] extensively studied the $\mathrm{FeF}_{3}$ reaction mechanism in two publications that appeared in 2003 and later in 2007 [18]. Again the study was carried on a commercially available product but this time, high energy ball milling was used both to decrease the fluoride particle sizes down to $25-30 \mathrm{~nm}$ and to intimately mix it with carbon-based conducting agents. Moreover, the studied voltage regions were varied from $4.5-2 \mathrm{~V}$ versus $\mathrm{Li}^{+} / \mathrm{Li}$ to 4.5-1.5 $\mathrm{V}$ versus $\mathrm{Li}^{+} / \mathrm{Li}$ which permitted the description of the full electrochemical reaction of $\mathrm{FeF}_{3}$.

Pure, anhydrous iron trifluoride possesses a hexagonal lattice belonging to the $\mathrm{R}-3 c$ space group. This structure lies between that of $\mathrm{ReO}_{3}$ (regular corner-shared octahedrons resulting in oxygen ccp array) and that of $\mathrm{PdF}_{3}$ (where octahedrons are also corner-shared but with fluorine in hcp array). These two structures can be derived from each other by simple rotation of the octahedrons. For the sake of simplicity then, we will describe $\mathrm{FeF}_{3}$ as having a " $\mathrm{ReO}_{3}$-type structure" where an alpha angle $\left(\alpha=58^{\circ}\right)$ transform the cubic structure into a hexagonal one. Open tunnels are present along the [012] (Fig. 1).

Resulting from the presence of these channels, the electrochemical reaction can be described as an initial insertion of $\mathrm{Li}^{+}$, although not completely topotactic, with a first electrochemical plateau at around $3.4 \mathrm{~V}$ followed by a conversion reaction producing $\mathrm{Fe}^{0}$ and $\mathrm{LiF}$ with a second plateau at around $2.1 \mathrm{~V}$ (Fig. 1). Shortly, $\mathrm{FeF}_{3}$ electrochemical discharge reaction with $\mathrm{Li}^{+}$can be written as:

$\mathrm{Li}^{+}+\mathrm{e}^{-}+\mathrm{FeF}_{3} \rightarrow$ Intercalated ' $\mathrm{LiFeF}_{3}$ ', (3.4 V)

$2 \mathrm{Li}^{+}+2 \mathrm{e}^{-}+$Intercalated ' $\mathrm{LiFeF}_{3}$ ' $\rightarrow 3 \mathrm{LiF}+\mathrm{Fe}(2.1 \mathrm{~V})$

This behavior was documented by numerous techniques among which in situ and ex situ X-ray diffraction (XRD), ex situ selected area electron diffraction (SAED), ex situ electron energy loss spectroscopy (EELS) and galvanostatic intermittent titration technique (GITT).

Based on XRD studies, it was concluded that since a topotactic insertion should result in no appreciable change in the intensities of XRD reflections, reaction 1 proceeds through two separate mechanisms [17]. The topotactic reaction can be observed up to a composition of roughly $\mathrm{Li}_{0.5} \mathrm{FeF}_{3}$ while large variations in unit cell volume can be observed for the remaining part of the curve up to around 1 $\mathrm{Li}^{+}$. The conversion reaction (reaction 2) then follows. On 

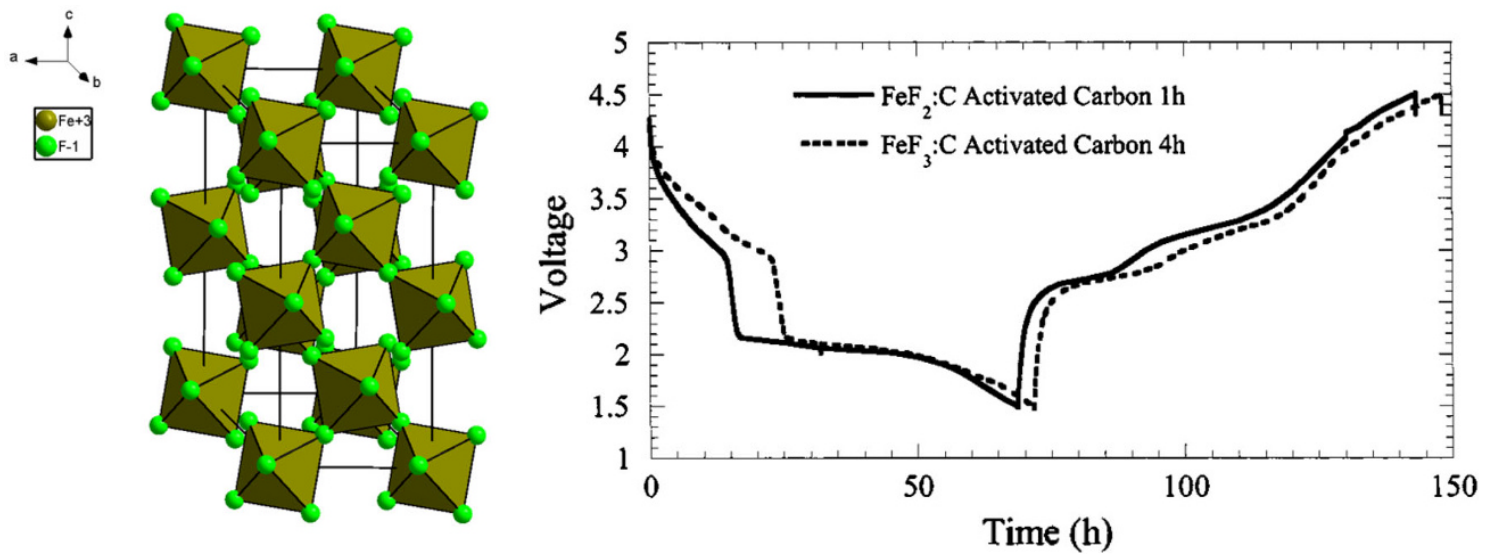

Fig. 1 Hexagonal unit cell of anhydrous $\mathrm{FeF}_{3}$ viewed along the (012) plane and its galvanostatic response (dotted line) vs. Li ${ }^{+} / \mathrm{Li}$. Reprinted with permission from Ref [17]. Copyright 2003, The Electrochemical Society

the other hand, the authors could not conclusively account for the charge behavior: unexpectedly identifying a compound related to $\mathrm{FeF}_{2}$ rutile structure at the end of charge, they were only able to exclude the presence of side reactions such as the formation of $\mathrm{FeC}_{x}$ or $\mathrm{FeO}_{x} \mathrm{~F}_{2-2 x}$ by electrolyte decomposition.

Through density functional theory (DFT), Doe et al. [19] identified several possible intermediate $\mathrm{Li}-\mathrm{Fe}-\mathrm{F}$ phases to explain both the discharge and charge behavior. Interestingly, they concluded that discharge and charge do not follow the same reaction path with the formation of a higher number of intermediate phases during charge than during discharge. Also, the final charge product resulted to be obtained from the delithiation of a rutile-like $\mathrm{Li}_{0.75} \mathrm{Fe}_{0.75} \mathrm{~F}_{3}$ phase thus forming a rutile-distorted $\mathrm{FeF}_{3}$ with cell parameters very close to those of $\mathrm{FeF}_{2}$.

Experimental proof of such a behavior was given almost concomitantly by Yamakawa et al. [20] through ex situ ${ }^{6} \mathrm{Li}$, ${ }^{7} \mathrm{Li}$ and ${ }^{19} \mathrm{~F}$ magic-angle-spinning nuclear magnetic resonance (MAS-NMR) among other techniques. The analyzed commercially available iron trifluoride was ball-milled with carbon. In order to clarify the end-of-charge mechanism, the authors used an interesting approach consisting in the comparison of an electrochemically cycled $\mathrm{FeF}_{3}$ sample with a $\mathrm{FeF}_{2}$ sample cycled with the same conditions. The reported results confirm the structural transformation of the initial $\mathrm{ReO}_{3}-\mathrm{FeF}_{3}$ phase into a phase structurally resembling a lithiated rutile with a stoichiometry close to $\mathrm{Li}_{0.5} \mathrm{FeF}_{3}$. The comparison with pure rutile- $\mathrm{FeF}_{2}$ showed that the Li local environments were similar to those of the $\mathrm{FeF}_{3}$ system lending further support to the experimental data. The transformation evolves initially through a twophase region (up to $x \sim 0.5$ ) and then through a solidsolution reaction that involves insertion of $\mathrm{Li}$ into $\mathrm{Li}_{0.5} \mathrm{FeF}_{3}$. Furthermore, the material can accommodate more lithium by progressively reducing the $\mathrm{Fe}$ and extruding $\mathrm{LiF}$ from the matrix reaching a final state where $\mathrm{LiF}$ and $\alpha-\mathrm{Fe}$ are intimately mixed. Interestingly, NMR spectra showed that the obtained $\alpha$-Fe is superparamagnetic and not ferromagnetic as one would expect. When the reconversion was studied, it was found that the LiF-Fe mix re-forms a lithiated rutile phase at $4.0 \mathrm{~V}$ with a composition close to $\mathrm{Li}_{0.5} \mathrm{FeF}_{3}$. The authors conclude then that the conversion reaction is largely, but not completely, reversible.

It is worth noting that the first insertion reaction (reaction 1) was very recently reinvestigated with the proposal of a simpler mechanism other than the separated two-phase region up to $\mathrm{Li}_{0.5} \mathrm{FeF}_{3}$ and solid-solution up to $\mathrm{LiFeF}_{3}$. Through in situ XRD, Tan et al. [21] proposed that lithiation involves a single, continuous, topotactic insertion of Li-ions in the range $0-1 \mathrm{Li}^{+}$. The insertion would take place along the body diagonal of the trifluoride unit cell only resulting in limited distortion of the lattice parameters as the shifts of the observed diffraction peaks seem to suggest.

While the electrochemical reactions are, at this point, largely understood, the reaction kinetics remained to be addressed, notably the evolution of the polarization during cycling and the interfacial behaviors. Liu et al. [22] published a complete electrochemical study coupling GITT with electrochemical impedance spectroscopy (EIS) in order to clarify the above-mentioned points. In order to compare with previous studies, a high energy ball-milled $\mathrm{FeF}_{3} /$ carbon composite was analyzed in the $4.5-1 \mathrm{~V}$ versus $\mathrm{Li}^{+} / \mathrm{Li}$ potential window. The authors observed that after the initial $\mathrm{Li}$ insertion, the formation of the $\mathrm{LiF} / \mathrm{Fe}$ nanocomposite resulted in a phase separation. This nanocomposite exhibits a large internal interface between $\mathrm{LiF}$ and $\mathrm{Fe}$ and its EIS signature is characterized by both high 
resistance (due to $\mathrm{LiF}$ insulating character) and high capacitance (due to the high interfacial surface). It is important to stress that this internal interface does not involve the electrolyte in any case and is purely limited to the interface inside the solid state composite. As one can expect, the phase separation results in a large overpotential which is experimentally observed as a strong polarization of $\mathrm{FeF}_{3}$ electrochemical curve. During charge, recombination involves migration of heavy atoms such as $\mathrm{Fe}$ and $\mathrm{F}$ to recover the rutile $\mathrm{Li}_{\mathrm{X}} \mathrm{FeF}_{3}(x \sim 0.5)$. This step is initially fast at the interface but soon slows down resulting in a limitation to the reaction rate.

As a final observation, the authors also implied that such a behavior arises when the reaction kinetics are faster at higher rates. In other words, rapidly reversing the $\mathrm{LiF} / \mathrm{Fe}$ nanocomposite is much more effective than let it rest for some time. This observation has, of course, important implications on the cell design should a commercial $\mathrm{FeF}_{3}$ based cathode see the daylight.

Apart the electrochemical mechanisms involved in the conversion reaction, studies devoted to analyzing other problems involving iron trifluoride in secondary cells appeared. For example, Zhou et al. [23-25] studied the thermal stability of the usually ball-milled commercial iron trifluoride/carbon mixture by thermogravimetry (TGADSC). They analyzed the thermal behavior of samples cycled limiting the discharge depths to $1 \mathrm{Li}, 2 \mathrm{Li}$ and $3 \mathrm{Li}$. It was demonstrated that $\mathrm{FeF}_{3}$ is thermally stable and that reaction peaks were observed only due to electrolyte decomposition. No appreciable reaction was observed for 1 and $2 \mathrm{Li}$ reactions except for the formation of a surface film due to the contact electrode-electrolyte (decomposing in the range $100-160^{\circ} \mathrm{C}$ ). It is interesting to point out, however, that the iron formed at the end of the complete conversion reaction $(3 \mathrm{Li})$ was found to react with $\mathrm{PF}_{5}$ present in the electrolyte (decomposition of $\mathrm{LiPF}_{6}$ ) at temperatures around $300{ }^{\circ} \mathrm{C}$.

\section{Synthesis techniques, new electroactive phases and approaches for the improvement of $\mathrm{FeF}_{3}$}

Besides the well-known mechanotreatment of commercial $\mathrm{FeF}_{3}$ powder, authors have been increasingly interested in the direct synthesis of the electroactive species by softchemistry approaches such as sol-gel or hydrothermal/ solvothermal methods. Iron trifluoride is generally obtained by treating the anhydrous trichloride in a flow of HF. The reaction at RT yields amorphous $\mathrm{FeF}_{3}$ while crystalline powders can be obtained after heat treatment (at least $600{ }^{\circ} \mathrm{C}$ ) [26]. This is obviously an expensive and complex procedure if one wants to produce larger quantities at the industrial scale.
Hydrated phases

The first report of a full synthesis of $\mathrm{a} \mathrm{FeF}_{3}$ based material at low $\mathrm{T}$ appeared in 2009 with the publication of $\mathrm{Wu}$ et al. [27, 28]. By reacting a $\mathrm{FeCl}_{3}$ water solution with $\mathrm{NaOH}$, the hydroxide $\mathrm{Fe}(\mathrm{OH})_{3}$ precipitates. This precipitate easily reacts with an excess of $\mathrm{HF}$ water solution to give a number of hydrated iron trifluorides some of which can be partially dehydrated in mild conditions $\left(70-150{ }^{\circ} \mathrm{C}\right.$ at atmospheric pressure or under vacuum). The obtained fluoride was then ball-milled together with $\mathrm{MoS}_{2}$ or $\mathrm{V}_{2} \mathrm{O}_{5}$ in order to promote the formation of a mixed conducting matrix to provide easier transport of both ions and electrons. Both samples exhibited interesting capacities (around 160 and $200 \mathrm{mAh} \mathrm{g}^{-1}$ for the $\mathrm{MoS}_{2}$ and the $\mathrm{V}_{2} \mathrm{O}_{5}$ composites, respectively, at $0.1{ }^{\circ} \mathrm{C}$ rate) for at least 30 cycles. However, the authors limited the cycles to a relatively narrow potential window of 4.5-2 $\mathrm{V} \mathrm{vs}^{+} / \mathrm{Li}$ thus exploiting only the part of the curve relative to the insertion reaction ( $c f$. Eq. 1). As one can imagine, some discrepancies in the electrochemical curves arise since in the reported composites $\mathrm{FeF}_{3}$ is actually hydrated and structurally different from the $\mathrm{ReO}_{3}$-type $\mathrm{FeF}_{3}$ phase. Thus, the intercalation potential is relatively lower decreasing from the $3.4-3 \mathrm{~V}$ for the anhydrous $\mathrm{ReO}_{3}$-type $\mathrm{FeF}_{3}$ phase [17] to the 3-2.6 $\mathrm{V}$ for the reported hydrated phase.

Recently Louvain et al. [3] published a comprehensive overview of the materials obtained when even small traces of water are present in the reaction media. Since $\mathrm{FeF}_{3}$ is highly hygroscopic, a number of $\mathrm{H}_{2} \mathrm{O}$-containing structures have been studied since the late 1960s resulting in a quite variegated picture. In general, both anhydrous $\mathrm{FeF}_{3}$ and all its partially hydrated forms are not stable in air at RT and will slowly accept water molecules until the $\mathrm{FeF}_{3} \cdot 3 \mathrm{H}_{2} \mathrm{O}$ stoichiometry is eventually reached. If the hydration

Table 1 Crystallographic parameters of the main iron trifluoride hydrated forms

\begin{tabular}{|c|c|c|c|c|c|c|c|c|}
\hline Structure & $\begin{array}{l}\text { Space } \\
\text { group }\end{array}$ & $a(\mathrm{pm})$ & $b(\mathrm{pm})$ & $c(\mathrm{pm})$ & $\begin{array}{l}\alpha \\
\left({ }^{\circ}\right)\end{array}$ & $\begin{array}{l}\beta \\
\left({ }^{\circ}\right)\end{array}$ & $\begin{array}{l}\gamma \\
\left({ }^{\circ}\right)\end{array}$ & $\mathrm{Z}$ \\
\hline $\begin{array}{l}\alpha-\mathrm{FeF}_{3} \cdot 3 \mathrm{H}_{2} \mathrm{O} \\
{[29]}\end{array}$ & $\mathrm{R}-3 m$ & 951.4 & 951.4 & 478.8 & 90 & 90 & 120 & 3 \\
\hline $\begin{array}{c}\beta-\mathrm{FeF}_{3} \cdot 3 \mathrm{H}_{2} \mathrm{O} \\
\mathrm{JCPDS} \\
32-0464\end{array}$ & $\mathrm{P} 4 / n$ & 784.6 & 784.6 & 387.7 & 90 & 90 & 90 & 2 \\
\hline $\begin{array}{l}\mathrm{FeF}_{3} \cdot 0.5 \mathrm{H}_{2} \mathrm{O} \\
\quad[30] \\
\text { (pyrochlore) }\end{array}$ & $\mathrm{F} d-3 m$ & 104.1 & 104.1 & 104.1 & 90 & 90 & 90 & 4 \\
\hline $\begin{array}{l}\mathrm{FeF}_{3} \cdot 0.33 \mathrm{H}_{2} \mathrm{O} \\
\mathrm{CPDS} 76-1216 \\
\text { (hexagonal } \\
\text { tungsten } \\
\text { bronze) }\end{array}$ & $\mathrm{Cmcm}$ & 742.3 & 1273.0 & 752.6 & 90 & 90 & 90 & 12 \\
\hline
\end{tabular}




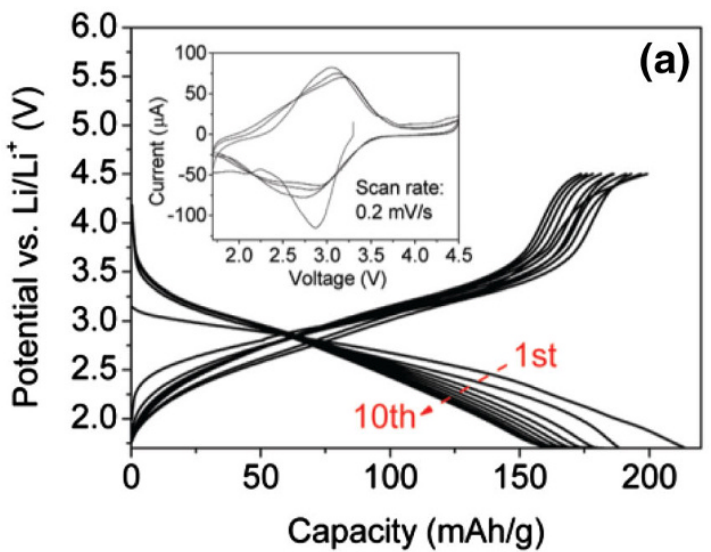

Fig. 2 Galvanostatic cycles of 5 wt \% SWCNTs composites of HTB$\mathrm{FeF}_{3} \cdot 0.33 \mathrm{H}_{2} \mathrm{O}$ (a) and pyrochlore- $\mathrm{FeF}_{3} \cdot 0.5 \mathrm{H}_{2} \mathrm{O}$ (b) in the voltage window $4.5-1.7 \mathrm{~V}$ vs. $\mathrm{Li}^{+} / \mathrm{Li}\left(0.1^{\circ} \mathrm{C}\right.$ rate $)$. The inset displays the

process is observed starting from the anhydrous form, a large series of stoichiometries can be obtained the most common of which are reported in Table 1. However, solution-based syntheses can also lead to mixed valence compounds such as: $\mathrm{Fe}_{2} \mathrm{~F}_{5} \cdot 7 \mathrm{H}_{2} \mathrm{O}, \mathrm{Fe}_{1.9} \mathrm{~F}_{4.75} \cdot 0.95 \mathrm{H}_{2} \mathrm{O}$ or $\mathrm{Fe}_{3} \mathrm{~F}_{8} \cdot 2 \mathrm{H}_{2} \mathrm{O}$ [3].

The picture is complicated also by the fact that both the pyrochlore and the hexagonal tungsten bronze (HTB) structures (see Table 1) can be obtained either in the fully dehydrated $\mathrm{FeF}_{3}$ form [3] or in the partially hydrolyzed form with substitution of $\mathrm{F}$ anions by $\mathrm{OH}$ groups. Considering for example the $\mathrm{HTB}-\mathrm{FeF}_{3} \cdot 0.33 \mathrm{H}_{2} \mathrm{O}$ structure, it is possible to obtain it through dehydration of $\mathrm{FeF}_{3} \cdot 3 \mathrm{H}_{2} \mathrm{O}$ $\left(T>120{ }^{\circ} \mathrm{C}\right.$ [3]). Further thermal treatment yields anhydrous $\mathrm{HTB}-\mathrm{FeF}_{3}$ [3] or an $\mathrm{OH}$ substituted structure such as HTB-FeF ${ }_{3}-{ }_{x}(\mathrm{OH})_{x} \cdot y \mathrm{H}_{2} \mathrm{O} \quad(y<0.33)$ [31-33]. By conventional structural analysis techniques, like $\mathrm{XRD}$, it cannot be clearly distinguished between these three forms so other means have to be deployed to analyze the material in detail. In particular Mößbauer spectroscopy can help due to its sensitivity to the atomic environment as well as by infrared (IR) spectroscopy after adsorption of small molecules (generally $\mathrm{NH}_{3}$ or pyridine).

In a series of studies, the group of Maier, demonstrated the electrochemical activity of both HTB and pyrochlore hydrated iron trifluorides [30, 34-38]. The synthesis involves $\mathrm{Fe}\left(\mathrm{NO}_{3}\right)_{3} \cdot 9 \mathrm{H}_{2} \mathrm{O}$ in 1-butyl-3-methylimidazolium tetrafluoroborate $\left(\mathrm{BmimBF}_{4}\right)$ ionic liquid at $50{ }^{\circ} \mathrm{C}$; the ionic liquid serving multiple roles at a time such as: solvent, soft template and fluorine source $\left(\mathrm{BF}_{4}{ }^{-}\right.$anion degrades to $\mathrm{BF}_{3}$ and $\mathrm{F}^{-}$in presence of water). Carbonaceous conductivity enhancers, such as single-walled carbon nanotubes (SWCNTs), can be added to the reaction medium to increase the overall electrochemical performances. The $\mathrm{HTB}-\mathrm{FeF}_{3} \cdot 0.33 \mathrm{H}_{2} \mathrm{O}$ structure is built around very

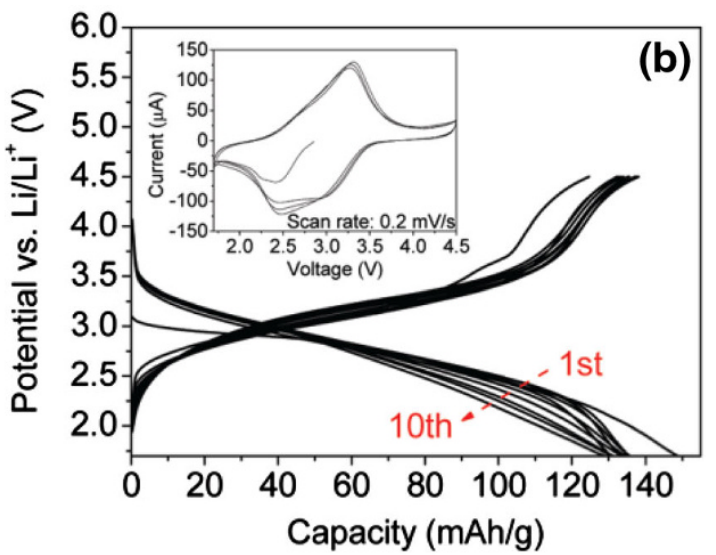

respective cyclic voltammograms at a constant scanning rate of $0.2 \mathrm{mV} \mathrm{s}^{-1}$. Adapted with permission from Ref [36]. Copyright 2011, American Chemical Society

large hexagonal cavities (around $550 \mathrm{pm}$ across) forming channels running in the [001] direction. Water molecules occupy $1 / 3$ of the total free positions in the channels. This water serves as a strong structural stabilizer during electrochemical lithiation with the possibility to accommodate $\mathrm{Li}^{+}$up to the full $2 / 3$ of the remaining vacant positions. $\mathrm{HTB}-\mathrm{FeF}_{3} \cdot 0.33 \mathrm{H}_{2} \mathrm{O}$ thus shows an intercalation behavior (solid solution) in the region $4.5-1.6 \mathrm{~V}$ versus $\mathrm{Li}^{+} / \mathrm{Li}$ with the possibility to reach the theoretical capacity of $150 \mathrm{mAh} \mathrm{g}^{-1}$ (Fig. 2a). The large cavity also permits fast $\mathrm{Li}^{+}$diffusion with good capacities retained even at $1{ }^{\circ} \mathrm{C}$ rates [35].

The pyrochlore- $\mathrm{FeF}_{3} \cdot 0.5 \mathrm{H}_{2} \mathrm{O}$ is also built around slightly smaller hexagonal cavities compared to the HTB homologue (around $500 \mathrm{pm}$ across), but the channels run in the [110] direction instead. However, pyrochlore is also a more unstable structure and it undergoes irreversible amorphisation at potentials below $1.6 \mathrm{~V}$. This phenomenon is due to the loss of structural water dislodged from the channels and has secondary consequences on partial electrolyte degradation [38]. However, the pyrochlore structure seems also to produce much better distributed composites with carbonaceous additives leading to a longer-lived cathode material $[30,36]$.

The same working group also demonstrated the capability of both structures through sodium intercalation with comparable $140-150 \mathrm{mAh} \mathrm{g}^{-1}$ in the region $4-1.2 \mathrm{~V}$ versus $\mathrm{Na}^{+} / \mathrm{Na}$ independent of the chosen compound [30, 37].

Following the direction traced with the synthetic method developed by the Maier's group, $\mathrm{Li}$ et al. [39] obtained a $\mathrm{HTB}-\mathrm{FeF}_{3} \cdot 0.33 \mathrm{H}_{2} \mathrm{O} /$ graphene nanosheets (GNS) composite. During synthesis, GNS are stabilized in ethanol by the addition of $\mathrm{BmimBF}_{4}$ ionic liquid which helps to avoid restacking due to the attraction between the $[\mathrm{Bmim}]^{+}$cation and the $\pi$-electrons of graphitic layers. The resulting 
Fig. 3 TEM (a) and galvanostatic cycling (b) of $\mathrm{FeF}_{3} \cdot 0.33 \mathrm{H}_{2} \mathrm{O} / \mathrm{RGO}$ composite at various $\mathrm{C}$ rates. Voltage window $4.4-1.6 \mathrm{~V}$ vs. $\mathrm{Li}^{+} / \mathrm{Li}$ as reported in Ref [41]
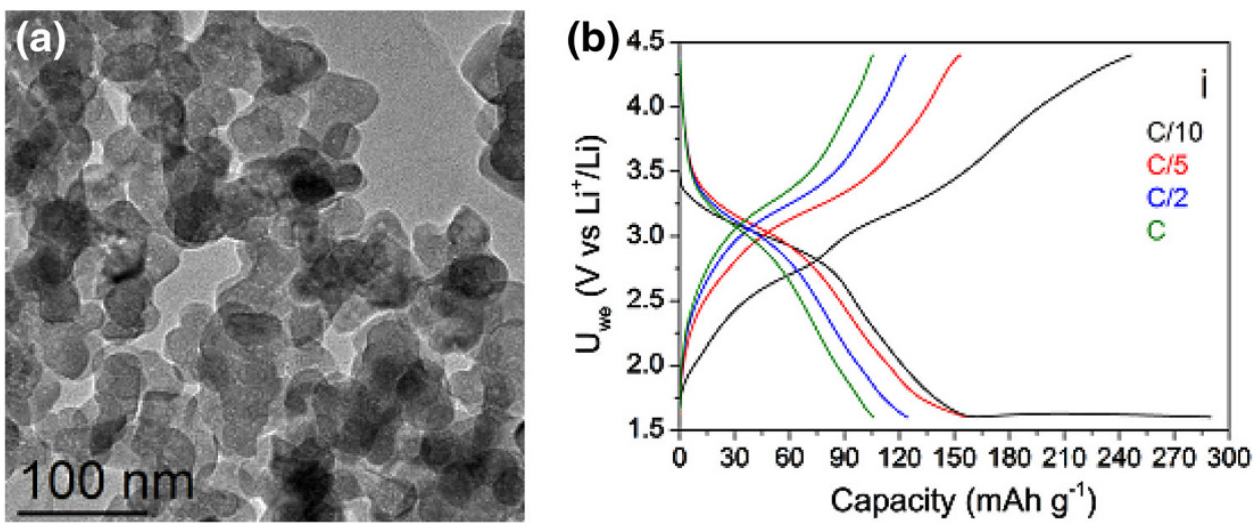

composite material shows much spaced fluoride particles, $10 \mathrm{~nm}$ in average, anchored on the graphene sheets even if a small percentage of the carbonaceous source remains after synthesis (less than $10 \mathrm{wt} \%$ from elemental analysis). In the insertion reaction electrochemical window (4.5-1.7 vs. $\left.\mathrm{Li}^{+} / \mathrm{Li}\right)$ a very good performance at the higher $\mathrm{C}$ rates was recorded $\left(90 \mathrm{mAh} \mathrm{g}^{-1}\right.$ at $20{ }^{\circ} \mathrm{C}$ rate) confirming the importance of a careful address of the electrical insulating nature of fluoride particles. Prolonged cycling showed a stability lasting for over 200 cycles at $10{ }^{\circ} \mathrm{C}$ rate.

Lu et al. [40] employed the same ionic liquid-based synthesis, but implemented it by microwave irradiation $\left(80{ }^{\circ} \mathrm{C}\right.$ for $\left.5 \mathrm{~min}\right)$. The authors obtained the pyrochlore type $\mathrm{FeF}_{3} \cdot 0.5 \mathrm{H}_{2} \mathrm{O}$ regardless of the amount of ionic liquid added to the reaction medium. However, the sample morphology is clearly influenced by the amount of ionic liquid and in particular with its increase, the resulting particle morphology changes from octahedrons to spheres with porous surface. These latter are most probably secondary particles (around $200 \mathrm{~nm}$ in diameter) formed by the agglomeration of smaller primary particles (as already observed by Li et al. [35, 38]). Electrochemical results for these porous spheres in the region $4.5-1.6$ versus $\mathrm{Li}^{+} / \mathrm{Li}$ are comparable to those reported for hydrated fluoride phases with an average of $140 \mathrm{mAh} \mathrm{g}^{-1}$ for 100 cycles at around $0.07{ }^{\circ} \mathrm{C}$ rate.

Microwave irradiation has been also exploited by $\mathrm{Di}$ Carlo et al. [41] who demonstrated an ionic-liquid-free approach to $\mathrm{HTB}_{\mathrm{FeF}} \cdot 0.33 \mathrm{H}_{2} \mathrm{O}$. In this study, the $\mathrm{BmimBF}_{4}$ ionic liquid was substituted by a methanolic solution of $\mathrm{HF}$ and a high boiling point alcohol acting as a solvent (benzyl alcohol). By microwave irradiation $\left(150{ }^{\circ} \mathrm{C}\right.$ for $\left.10 \mathrm{~min}\right)$, both a pure product and a reduced graphene oxide-based composite have been successfully synthesized with the formation of $\mathrm{C}-\mathrm{F}$ bonds between fluoride particles and the carbonaceous substrate (Fig. 3).

The latter in particular, was easily capable of cycling at its full theoretical capacity after more than 50 cycles but, in a more interesting way, it showed the possibility of delivering a quite stable $100 \mathrm{mAh} \mathrm{g}^{-1}$ at $1{ }^{\circ} \mathrm{C}$ rate in the potential window 4.4-1.6 versus $\mathrm{Li}^{+} / \mathrm{Li}$.

Very recently, also ball-milling has been revisited for the direct synthesis of $\mathrm{HTB}-\mathrm{FeF}_{3} \cdot 0.33 \mathrm{H}_{2} \mathrm{O}$-acetylene black composites [42]. $\mathrm{Fe}\left(\mathrm{NO}_{3}\right)_{3} \cdot 9 \mathrm{H}_{2} \mathrm{O}$ and acetylene black react with $\mathrm{NH}_{4} \mathrm{~F}$ in an ethanol/polyethylene glycol mixture $(1: 1$ volume) for $10 \mathrm{~h}$ in stainless steel milling vessels. A mild heat treatment to remove $\mathrm{NH}_{4} \mathrm{NO}_{3}$ follows $\left(120{ }^{\circ} \mathrm{C}, 24 \mathrm{~h}\right)$. However, unlike in previous examples where a link between the carbon and the fluoride particles can be identified in the form of $\mathrm{C}-\mathrm{F}$ bonds $[30,41]$, there is no evidence of chemical reaction for this composite, suggesting a behavior more related to intimate mixing/coating than to real bonding between the fluoride particles and the carbonaceous matrix. Electrochemical results are in line

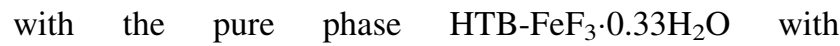
$150 \mathrm{mAh} \mathrm{g}^{-1}$ delivered at $0.1{ }^{\circ} \mathrm{C}$ rate in the potential window 4.4-1.5 versus $\mathrm{Li}^{+} / \mathrm{Li}$.

Besides carbonaceous additives, another approach to improve the electronic conductivity of iron trifluoride is doping with other transition metals. As it has been predicted that Co substitution can extensively decrease the band gap from $4.49 \mathrm{eV}$ for the pure fluoride to $1.46 \mathrm{eV}$ for $\mathrm{Co}_{0.5} \mathrm{Fe}_{0.5} \mathrm{~F}_{3}$ [43], experimental proof soon followed. In the study of Liu et al. [44], Co-doped $\mathrm{FeF}_{3}$ was prepared by precipitation in water $\left(\mathrm{FeCl}_{3} \cdot 6 \mathrm{H}_{2} \mathrm{O}, \mathrm{CoCl}_{2} \cdot 6 \mathrm{H}_{2} \mathrm{O}\right.$ and $\mathrm{NaOH})$. The resulting hydroxide was then dissolved in concentrated $\mathrm{HF}$ (40 wt \% in $\mathrm{H}_{2} \mathrm{O}$ ) at RT and heat-treated at $170{ }^{\circ} \mathrm{C}$ (12 $\mathrm{h}$ under argon). Ball milling with acetylene black (15 wt \%) yielded composites of general formula: $\mathrm{Fe}_{1}-{ }_{x} \mathrm{Co}_{x} \mathrm{~F}_{3} / \mathrm{C}$, which underwent further annealing at $150{ }^{\circ} \mathrm{C}$ for $3 \mathrm{~h}$. The resulting fluoride-based composite does not show signs of phase separation by XRD. The primary phase is ascertained to be a doped HTB$\mathrm{FeF}_{3} \cdot 0.33 \mathrm{H}_{2} \mathrm{O}$ with slightly smaller cell volume consistent with the smaller ionic radius of $\mathrm{Co}$ (III) compared to $\mathrm{Fe}$ (III). The best electrochemical response was obtained for the composition $\mathrm{Fe}_{0.95} \mathrm{Co}_{0.05} \mathrm{~F}_{3} / \mathrm{C}$ although only the $4.5-2 \mathrm{~V}$ versus $\mathrm{Li}^{+} / \mathrm{Li}$ window was analyzed (Fig. 4). The 

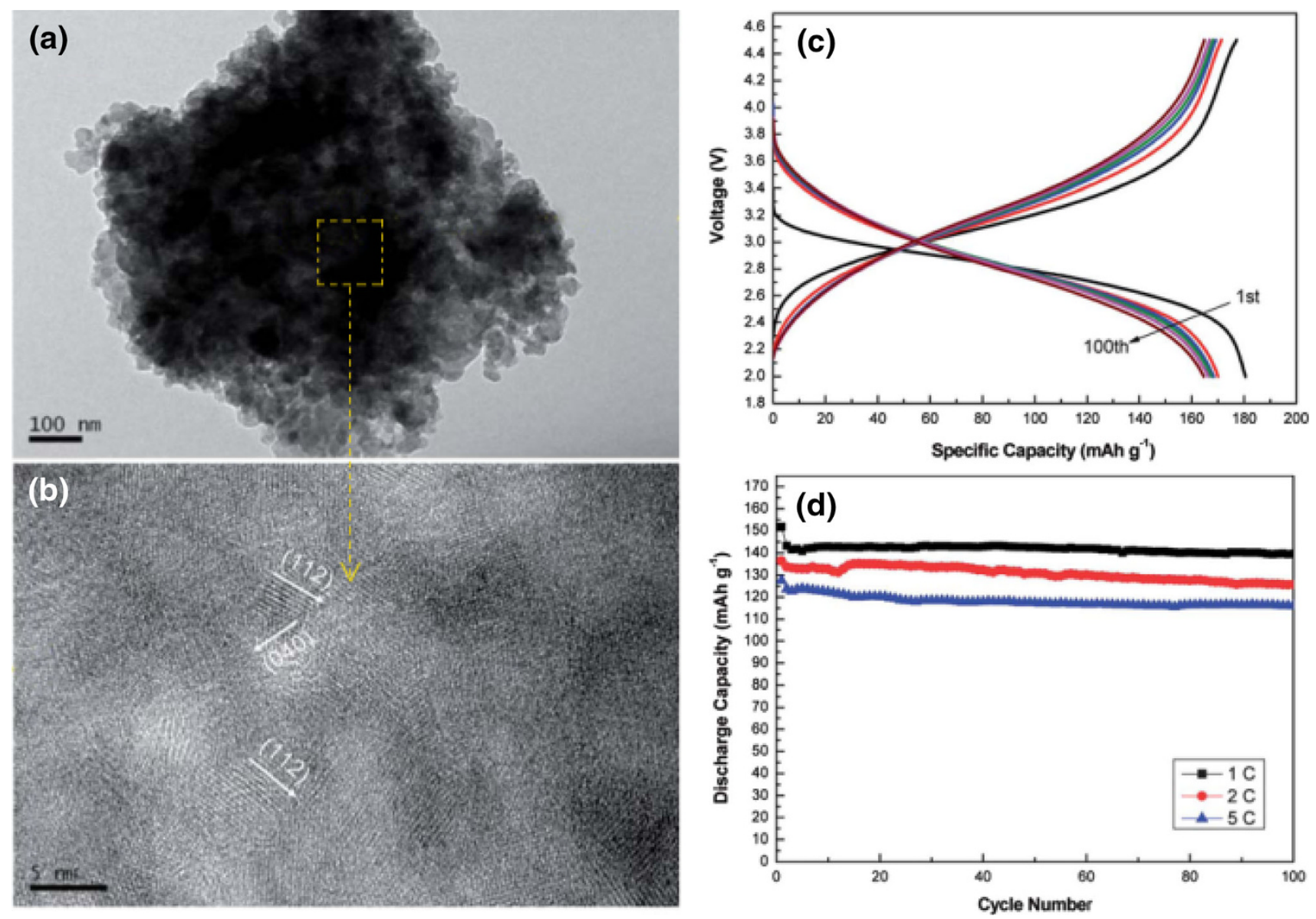

Fig. 4 TEM (a) and HR-TEM (b) images of $\mathrm{Fe}_{0.95} \mathrm{Co}_{0.05} \mathrm{~F}_{3} / \mathrm{C}$ composite. Primary particles of around $10 \mathrm{~nm}$. Galvanostatic cycling of the composite $\left(0.5^{\circ} \mathrm{C}\right.$ rate $)$ and its cycling behavior at various $\mathrm{C}$

composite was able to deliver around $160 \mathrm{mAh} \mathrm{g}^{-1}$ after 100 cycles at $0.5^{\circ} \mathrm{C}$ and no fading was recorded for the same prolonged cycling at increased $\mathrm{C}$ rates. Further analysis based on the GITT technique confirmed the beneficial effect of doping demonstrating an increased $\mathrm{Li}^{+}$diffusion coefficient of $2 \times 10^{-12} \mathrm{~cm}^{2} \mathrm{~s}^{-1}$ at around $2.7 \mathrm{~V}$ versus $\mathrm{Li}^{+} / \mathrm{Li}$ (midway of 1 st discharge). For the sake of comparison, $\mathrm{Li}$ et al. reported an average value close to $10^{-14} \mathrm{~cm}^{2} \mathrm{~s}^{-1}$ for the pure, non-milled HTB$\mathrm{FeF}_{3} \cdot 0.33 \mathrm{H}_{2} \mathrm{O}$ considering aggregates of around $350 \mathrm{~nm}$ [35].

In a recent publication, Liu et al. [45] compared the electrochemical response of anhydrous $\mathrm{FeF}_{3}$, of HTB$\mathrm{FeF}_{3} \cdot 0.33 \mathrm{H}_{2} \mathrm{O}$ and of the highly hydrated $\mathrm{FeF}_{3} \cdot 3 \mathrm{H}_{2} \mathrm{O}$. Interestingly, the three phases have similar behaviors in the enlarged voltage region $4.5-1 \mathrm{~V}$ versus $\mathrm{Li}^{+} / \mathrm{Li}$ with an initial plateau appearing in the region 3-2 $\mathrm{V}$ related to the insertion reaction and a second plateau below $1.7 \mathrm{~V}$. The authors conclude that the HTB structure shows the best electrochemical performances during the intercalation process, but loss of structural order leads to increased rates are shown in (c, d), respectively. Voltage window 4.5-2 V vs. $\mathrm{Li}^{+} / \mathrm{Li}$ as reported in Ref [44]. Images are courtesy of $\mathrm{X}$. Wang, adapted with permission

performance degradation when the conversion reaction is included.

Regardless, some studies focused on the fully hydrate phase: $\mathrm{FeF}_{3} \cdot 3 \mathrm{H}_{2} \mathrm{O}$. The $\mathrm{FeF}_{3} \cdot 3 \mathrm{H}_{2} \mathrm{O}$ structure is built around chains of apex-sharing octahedrons running along the [001] direction. In the apex positions, two fluorine atoms are arranged, while the four basal positions are statistically occupied by either fluorine or water (two of each). Each octahedron chain is then surrounded by four chains of exclusively water molecules, which create large spaces between each octahedron sequence originating roughly rectangular cavities around $46 \mathrm{pm}$ long and $26 \mathrm{pm}$ large. Since, unlike in $\mathrm{HTB}-\mathrm{FeF}_{3} \cdot 0.33 \mathrm{H}_{2} \mathrm{O}$, water molecules do not occupy the free positions in the channels, the structure is stabilized without further effect on $\mathrm{Li}^{+}$diffusion. Thus, in principle, during the intercalation process $\mathrm{Li}^{+}$diffusivity should be higher in $\mathrm{FeF}_{3} \cdot 3 \mathrm{H}_{2} \mathrm{O}$ than in HTB$\mathrm{FeF}_{3} \cdot 0.33 \mathrm{H}_{2} \mathrm{O}$.

Shi et al. [46] obtained the tri-hydrate by simple precipitation $\left(\mathrm{FeCl}_{3}\right.$-cetyl-trimethylammonium bromide surfactant, CTAB, -HF mixed water solution), while 

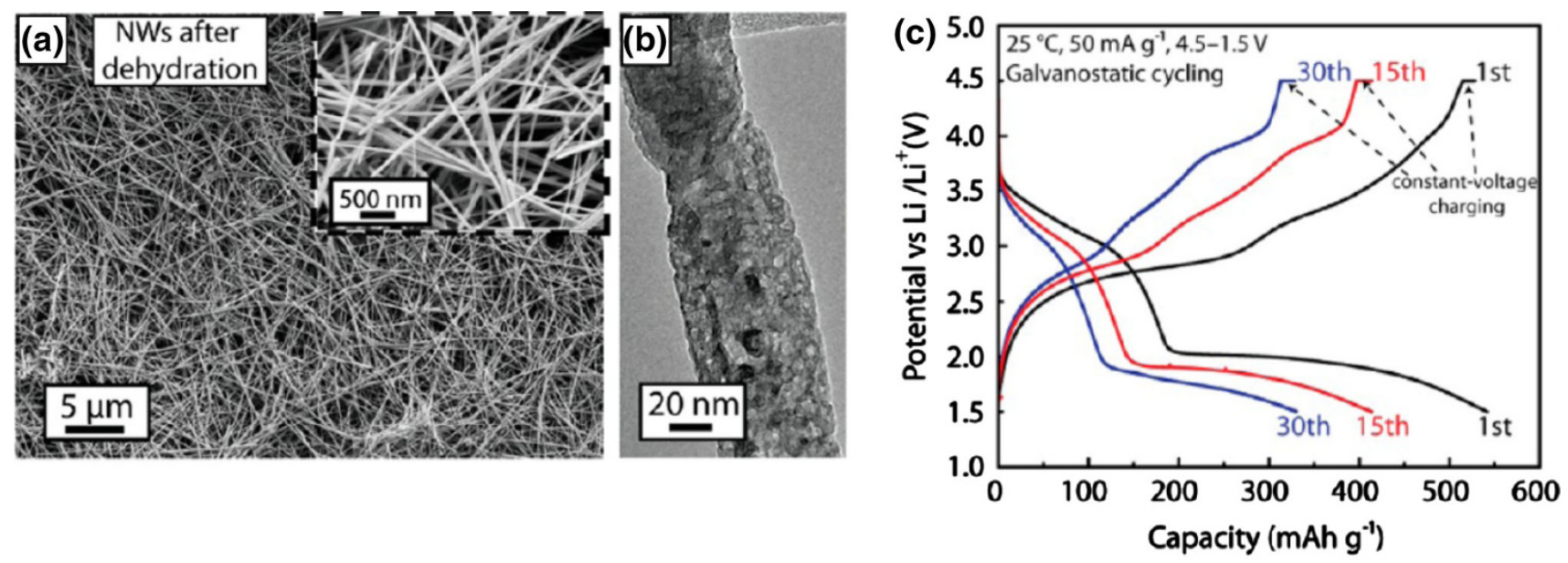

Fig. 5 SEM (a) and TEM (b) images of the iron fluoride wires after annealing with their relative galvanostatic cycles (c).Voltage window 4.5-1.5 V vs. $\mathrm{Li}^{+} / \mathrm{Li}\left(\sim 0.07{ }^{\circ} \mathrm{C}\right.$ rate). Adapted with permission from Ref [48]. Copyright 2012, American Chemical Society

composites were obtained after ball milling with carbon black. Analysis based on cyclic voltammetry results (CV) confirmed the assumption of a better $\mathrm{Li}^{+}$diffusivity demonstrating an increased $\mathrm{Li}^{+}$diffusion coefficient of $7 \times 10^{-13} \mathrm{~cm}^{2} \mathrm{~s}^{-1}$ at RT. For the sake of comparison, $\mathrm{Li}$ et al. [35] reported an average value close to $10^{-14} \mathrm{~cm}^{2} \mathrm{~s}^{-1}$ for the pure, non-milled $\mathrm{HTB}-\mathrm{FeF}_{3} \cdot 0.33 \mathrm{H}_{2} \mathrm{O}$ considering aggregates of around $350 \mathrm{~nm}$. The tri-hydrated fluoride also delivers a robust $210-200 \mathrm{mAh} \mathrm{g}^{-1}$ in the region $4.5-1.5 \mathrm{~V}$ versus $\mathrm{Li}^{+} / \mathrm{Li}$ at $0.1{ }^{\circ} \mathrm{C}$ rate for at least 30 cycles. However, unless the structure can be stabilized in some way, the instability due to the loss of structural water results in a tendency to steady performance degradation with cycling.

Synthesis followed by a post-treatment

For the synthesis of water-free $\mathrm{ReO}_{3}$-type $\mathrm{FeF}_{3}$ except for solid state reactions, a post-treatment to eliminate structural water is needed. In most of the cases, a second treatment is also involved, allowing particle size reduction, intimate mix with carbon additives or the formation of specific structures. In this section, we will examine the various reports which have appeared on this specific subject.

\section{Simple heat treatment for water removal}

One common synthesis method is the simple precipitation usually involving an ethanol or water solution of $\mathrm{FeCl}_{3}$ or $\mathrm{Fe}\left(\mathrm{NO}_{3}\right)_{3}$ mixed with an ethanol or water solution of $\mathrm{HF}$ or other fluorine source $\left(\mathrm{NH}_{4} \mathrm{HF}_{2}\right.$ for example). Surfactants, like CTAB, or carbon additives (carbon nanotubes, graphene oxide or reduced graphene oxide, etc.) are sometimes added to the reaction mixture in order to limit particle growth or provide the needed electronic conduction enhancement. Products are then submitted to a dehydration step by annealing (generally not above $400{ }^{\circ} \mathrm{C}$ ).

In their report, $\mathrm{Li}$ et al. $[47,48]$ employed a precipitation method followed by a dehydration step $\left(2{ }^{\circ} \mathrm{C} \min ^{-1}\right.$, $350{ }^{\circ} \mathrm{C}$ under $\mathrm{Ar}$ ). The obtained material consists of $\mathrm{ReO}_{3}-$ $\mathrm{FeF}_{3}$ with only trace amounts of $\mathrm{FeF}_{2}$ impurity. The peculiarity about the mentioned work is that a large excess of $\mathrm{HF}$ is used in respect to the Fe precursor (roughly 420 times). This large difference favors the growth of fluoride wires several hundreds of micrometers long and, in average, 80 (pristine) to $50 \mathrm{~nm}$ thick (after annealing, Fig. 5a, b). The authors attribute the preferential $1 \mathrm{D}$ growth to the formation of screw dislocations [49] also helped by the fact that $\mathrm{F}^{-}$is a good complexing ligand for $\mathrm{Fe}^{3+}$ and stabilizes the $\mathrm{FeF}_{6}{ }^{3-}$ complexes. The wires could be successfully cycled with only the customary addition of carbon black during electrode preparation (20 wt \%, Fig. 4c).

This publication [48] reports also an important insight in the electrochemical reaction of these fibers. From TEM observations on fully discharged electrodes, single-crystal $\alpha$-Fe nanodomains (3-5 nm) are formed consistently with the already described conversion reaction. However, these nanoparticles clearly appear to be interconnected through their common [110] family of planes to form a continuous network. Such a behavior, although never reported for the trifluoride, was recently demonstrated to occur for $\mathrm{a} \mathrm{FeF}_{2} / \mathrm{C}$ composite and was ascribed to the small diffusivity of $\mathrm{Fe}$ ions thus producing a metallic iron backbone encapsulated in $\mathrm{LiF}$ [50]. On the other hand, upon charge the usual reconversion to defective trirutile is observed but the reaction is constantly hindered up to complete electrode failure. At the 50th charge, significant amounts of unconverted $\mathrm{LiF}$ and $\alpha-\mathrm{Fe}$ are present but the exact reason of such degradation is still to be reported. 


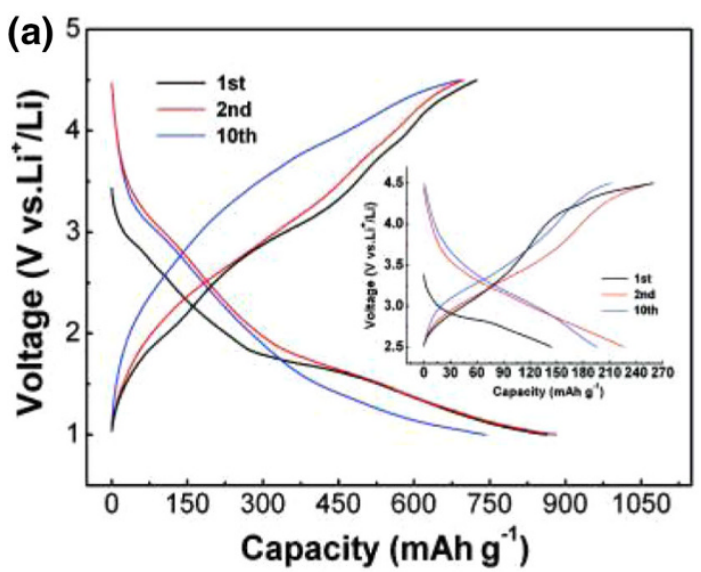

Fig. 6 a Galvanostatic cycles of one of the trifluoride composite electrodes described by $\mathrm{Li}$ et al. The inset displays the galvanostatic behaviors of the composite in the voltage window $4.5-2.5 \mathrm{~V} \mathrm{vs.} \mathrm{Li}^{+}$/

Other papers involve drying after precipitation either without [51] or with the presence of carbonaceous additives (for example reduced graphene oxide [52] or carbon nanotubes [53]). In the three above cases, however, although the authors provide XRD signatures suggesting full dehydration of $\mathrm{FeF}_{3} \cdot 3 \mathrm{H}_{2} \mathrm{O}$ to $\mathrm{ReO}_{3}$-type $\mathrm{FeF}_{3}$, the reported electrochemical signatures in the region 4.5-1.5 versus $\mathrm{Li}^{+} / \mathrm{Li}$ are very close to that of the hydrated phases (HTB or pyrochlore) suggesting either water presence in the compounds or partial dehydration/hydrolysis as discussed for the hydrated phases in the previous section [3133]. The group of Maier [37, 38] clearly observed that the final fluoride product is highly influenced both by the initial reaction $\mathrm{T}$ (for example, carrying on a reaction at $0{ }^{\circ} \mathrm{C}$ yielded a completely amorphous fluoride) and by the reaction medium (for example, the dehydration process carried in a hydrophobic ionic liquid yielded an almost amorphous product). So far, no comprehensive study has appeared on this particular issue which certainly is worth exploring.

Li et al. [54] examined the influence of three different synthetic routes involving $\mathrm{Fe}\left(\mathrm{NO}_{3}\right)_{3}$ and $\mathrm{NH}_{4} \mathrm{HF}_{2}$ mixed with different surfactants. In any case, annealing $\left(400{ }^{\circ} \mathrm{C}\right.$ under Ar) and ball milling (with graphite) were necessary in order to obtain a viable material. However, well dispersed $15 \mathrm{~nm}$ particles showed a very high capacity of around $800 \mathrm{mAh} \mathrm{g}^{-1}$ stable for at least 10 cycles at roughly $0.14{ }^{\circ} \mathrm{C}$ rate (Fig. 6). Extra capacity could be partially attributed to interfacial storage (see "Thin films" for a more complete explanation of this phenomenon), while the impressive features at high and very high current densities can be the effect of an important carbon load (52\% of the electrode mass) diluting the active material and increasing the electroactive surface area as postulated by the authors themselves.

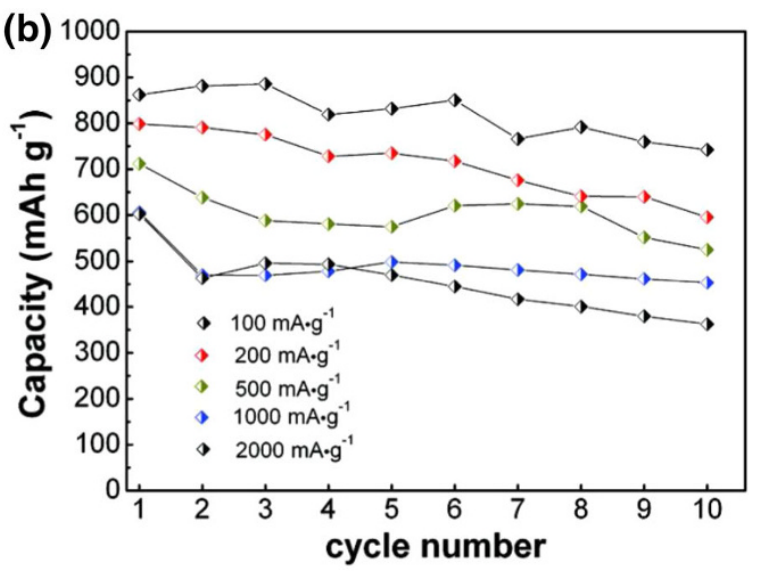

$\mathrm{Li}$ while the relative cycling performances at various rates are reported in b. Adapted with permission from Ref [54]. Copyright 2010, American Chemical Society

\section{Coating: carbonaceous additives and protective oxides}

The most common coating process involves the addition carbonaceous additives which are known to greatly enhance electronic conductivity of the electroactive material. For fluorides, graphene oxide/reduced graphene oxide (or graphene nanosheets as they are sometimes called) are the most widely used additives. Although carbonization of a carbon source (such as citric acid, a sugar or other compound) is often used to coat cathode materials such as $\mathrm{LiFePO}_{4}$ at high temperatures (e.g., $650{ }^{\circ} \mathrm{C}$ [55]), these temperatures are not compatible with transition metal fluorides. HF evolution (resulting in structure decomposition) for the HTB structure can be recorded as low as $170{ }^{\circ} \mathrm{C}$ under Ar atmosphere, practically as soon as water is removed from the hexagonal channels [32]. For this reason, it is important to study coating procedures that can be carried on at lower temperatures.

Addition of graphene/reduced graphene oxide to the precipitation mixture was reported by Liu et al. [56]. The results in terms of XRD signatures, both before and after the heat treatment $\left(150{ }^{\circ} \mathrm{C}\right.$ for $10 \mathrm{~h}$ in $\mathrm{N}_{2}$ flow), are very similar to the ones reported by Kim et al. [53] but the electrochemical signature $\left(4.5-1.5\right.$ versus $\left.\mathrm{Li}^{+} / \mathrm{Li}\right)$ is close to that of amorphous $\mathrm{FeF}_{3}$ reported by $\mathrm{Li}$ et al. [38] suggesting either water presence in the compounds or a partially amorphous state as previously discussed. However, in the wider potential window, the graphene-based composite seems to withstand cycling in a much better way. For example, the carbon nanotube-based composite reported by Kim delivers around $400 \mathrm{mAh} \mathrm{g}^{-1}$ after 10 cycles at $0.07{ }^{\circ} \mathrm{C}$, while the performance of the amorphous $\mathrm{FeF}_{3}$ reported by Li steadily degrades up to the 20th cycle where $250 \mathrm{mAh} \mathrm{g}^{-1}$ are registered at $0.1{ }^{\circ} \mathrm{C}$ rate. In comparison, the capacity of the graphene/reduced graphene oxide-based 

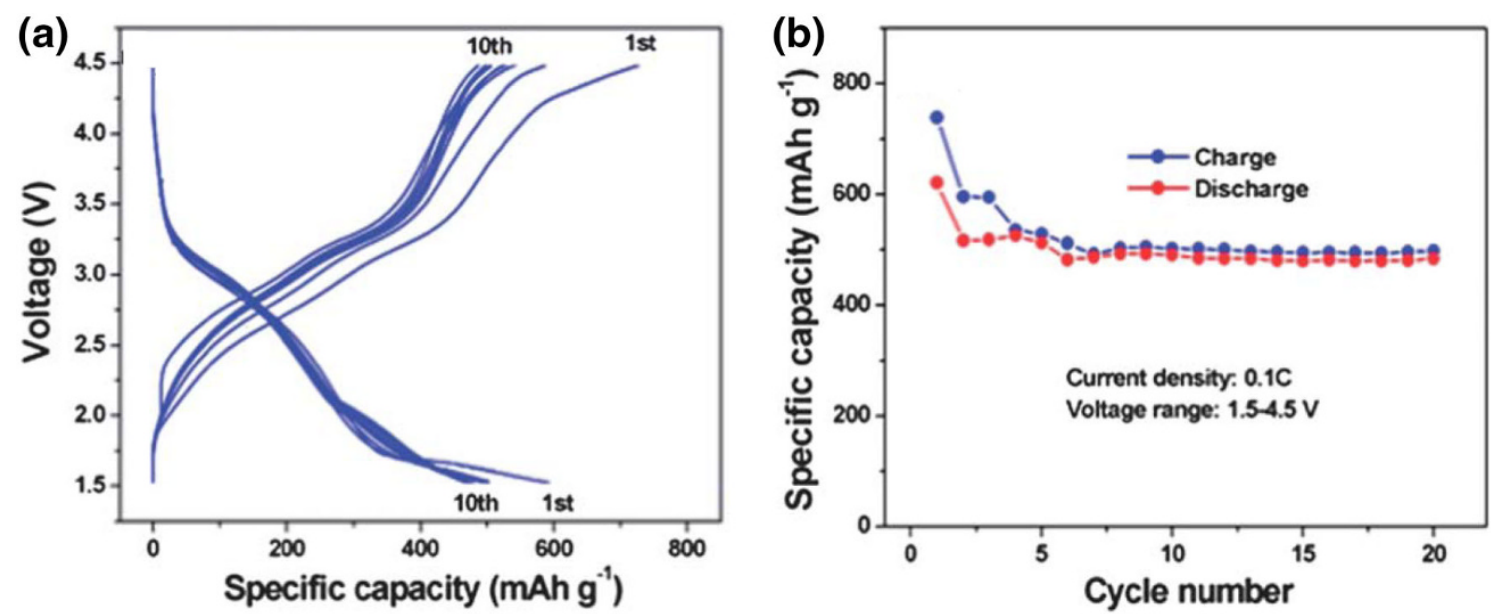

Fig. 7 Galvanostatic cycling (a) and cycling behavior (b) of the iron fluoride graphene/reduced graphene oxide composite. Voltage window 4.5-1.5 V vs. $\mathrm{Li}^{+} / \mathrm{Li}$ as reported in $\operatorname{Ref}[56]\left(0.1^{\circ} \mathrm{C}\right.$ rate). Images are courtesy of Y. Zhou, adapted with permission

composite stabilizes at $500 \mathrm{mAh}^{-1}$ delivered for at least 20 cycles at $0.1{ }^{\circ} \mathrm{C}$ rate (Fig. 7).

Another graphene/reduced graphene oxide composite was reported by $\mathrm{Ma}$ et al. [57] through a rather convoluted synthesis involving various steps. In a first step, $\mathrm{Fe}_{3} \mathrm{O}_{4} / \mathrm{C}$ composites were obtained from graphene oxide, sodium acetate $(\mathrm{NaAc})$ and $\mathrm{FeCl}_{3} \cdot 6 \mathrm{H}_{2} \mathrm{O}$ dissolved in ethylene glycol (EG) and solvothermally treated at $200{ }^{\circ} \mathrm{C}$ for $12 \mathrm{~h}$. An annealing step $\left(500{ }^{\circ} \mathrm{C}, 2 \mathrm{~h}, \mathrm{Ar} / \mathrm{H}_{2}\right.$ atmosphere) was carried out in order to reduce (at least partially) graphene oxide. The composite was solvothermally treated a second time with $\mathrm{HF}$ (48 wt $\% \mathrm{H}_{2} \mathrm{O}$ solution) to transform $\mathrm{Fe}_{3} \mathrm{O}_{4} /$ $\mathrm{C}$ into $\mathrm{FeF}_{3} \cdot 3 \mathrm{H}_{2} \mathrm{O} / \mathrm{C}$. Further annealing $\left(200{ }^{\circ} \mathrm{C}, 4 \mathrm{~h}, \mathrm{Ar}\right.$ atmosphere) yields $\mathrm{FeF}_{3} / \mathrm{C}$. The first annealing step, promotes the formation of few hundreds nanometer iron oxide particles. This greatly hinders the electrochemical reaction with a fast degradation from 600 to $230 \mathrm{mAh} \mathrm{g}^{-1}$ after the first five cycles even at very low current density (4.5-1.5 versus $\mathrm{Li}^{+} / \mathrm{Li}$ at $0.03{ }^{\circ} \mathrm{C}$ ). However, the benefic effect of the intimate contact and, possibly, the anchoring on the reduced graphene oxide additive can be observed on the long period when the large crystals have been repeatedly ground by the protracted conversion reaction. In fact, the composites are stable at around $200 \mathrm{mAh} \mathrm{g}^{-1}$ for at least 100 cycles. A similar result can be obtained using commercial $\mathrm{Fe}_{2} \mathrm{O}_{3}$ [58] instead of magnetite nanoparticles.

It is worth noting that other examples of addition of carbonaceous additives have been reported in "Hydrated phases", namely, in the works of Maier [30, 34, 36] and Di Carlo [41] but we chose to illustrate them in a different section due to the differences in the obtained fluoride product.

Another interesting concept is the coating of cathodic materials with oxides. The reason for coating is the fact that since direct contact with the electrolyte is prevented, dissolution of the cathode material due to the decomposition of $\mathrm{LiPF}_{6}$ is also hindered. Moreover, other benefits have been observed such as: maintenance of ionic conduction pathways, suppression of the release of oxygen and of phase transitions (in case of high-energy materials such as the solid solution $\mathrm{Li}_{2} \mathrm{MnO}_{3} / \mathrm{LiMO}_{2}$, with $\mathrm{M}=$ transition metal), and decrease of cationic disorder [59].

Following this approach, Zhang et al. [60] used the oxide coating concept but with the added benefit of increased electronic conductivity. Anhydrous $\mathrm{FeF}_{3}$ was thus coated with a thin layer of semiconductive $\alpha-\mathrm{Fe}_{2} \mathrm{O}_{3}$ (hematite) and showed improved electrochemical properties without further addition of carbonaceous additives and/ or ball milling. The synthesis of such a composite material involves the synthesis of hematite first (highly agglomerated particles of 100-150 nm) by a sol-gel method (a water solution of $\mathrm{Fe}\left(\mathrm{NO}_{3}\right)_{3} \cdot 9 \mathrm{H}_{2} \mathrm{O}$, citric acid and $\mathrm{NH}_{4} \mathrm{OH}$ is left to gelify and then heat-treated at $500{ }^{\circ} \mathrm{C}, 5 \mathrm{~h}$ under air). The resulting oxide is then fully fluorinated by further heat treatment $\left(475{ }^{\circ} \mathrm{C}, 5 \mathrm{~h}\right.$ under inert gas containing $\left.\mathrm{F}_{2}\right)$ and rapidly re-oxidized under air $\left(500{ }^{\circ} \mathrm{C}\right.$ for a duration varying from 15 to $480 \mathrm{~s})$. The electrochemistry reported in the potential window $4.5-1.2 \mathrm{~V}$ versus $\mathrm{Li}^{+} / \mathrm{Li}(0.07 \mathrm{C})$ is the result of the complex interaction between various active species: the primary $\mathrm{FeF}_{3}$, the $\mathrm{Fe}_{2} \mathrm{O}_{3}$ coating and possibly interfacial oxyfluoride formed between the two contiguous layers. Even though, the authors state that: "[...] the improvement of electrochemical performance of $\mathrm{FeF}_{3}$ resulting from an in situ $\mathrm{Fe}_{2} \mathrm{O}_{3}$ coating is inferior to that by mixing with carbon-based conductive additives", it is remarkable that such large particles can sustain some cycling without any further treatment to reduce size and/or further enhance electronic conductivity (roughly $260 \mathrm{mAh} \mathrm{g}^{-1}$ are delivered after 10 cycles). 
Fig. 8 a TEM image of the final $\mathrm{FeF}_{3} / \mathrm{PEODT}$ composite.

Pore size distribution, from BET analysis, is bimodal and centered at around 7 and $30 \mathrm{~nm}$ b Cycling behavior at various temperatures $\left(1.4^{\circ} \mathrm{C}\right.$ rate $)$ Voltage window $4.5-2 \mathrm{~V}$ vs. $\mathrm{Li}^{+} / \mathrm{Li}$ as reported in $\mathrm{Ref}[62]$. Images are courtesy of X. Zhang, adapted with permission
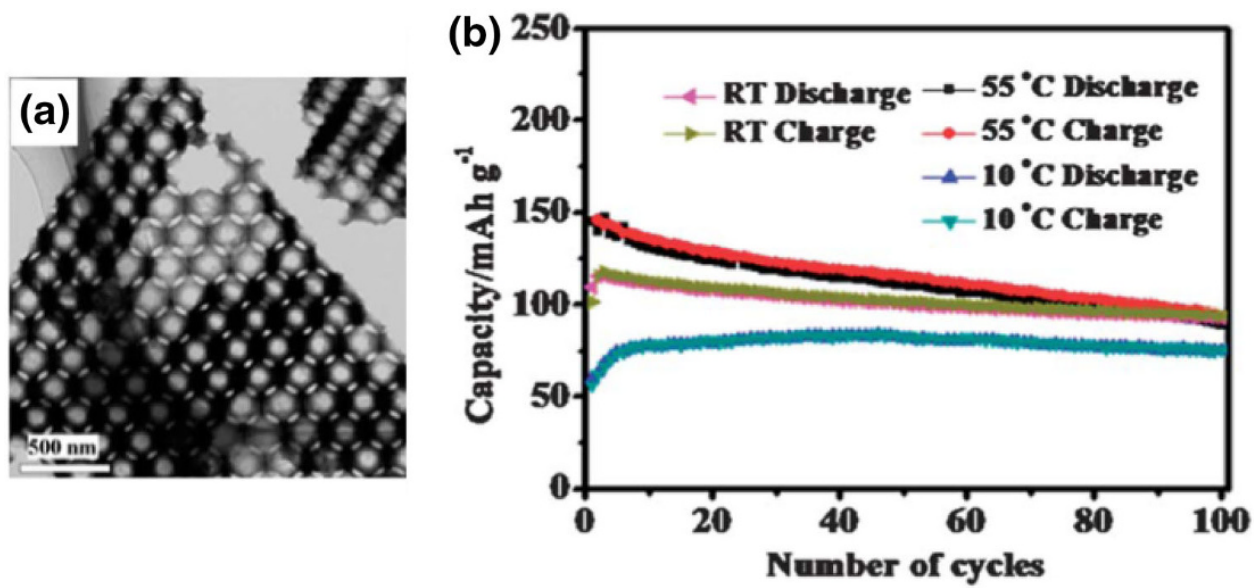

\section{Structuration}

In recent years the benefits of ordered three-dimensional (3D) porous nanostructures over nanopowders have widely taken root in the energy-materials community because they result in higher surface areas and more favorable structural stability over simple non-ordered particles. Moreover, the ameliorated diffusivity of the electrolyte through channels and pores would ensure a high specific surface area in contact with the electrode and hence an increased possibility for Li-ions to react. In the specific case of fluorides, there could also be an additional positive effect due to the minimization of nanoparticle aggregation induced by the conversion reaction [61].

An approach to the $3 \mathrm{D}$ structuration of the composite material has been reported by Ma et al. [62] who proposed three-dimensionally ordered macroporous (3DOM) structures coated with a conductive material (in this case, polyethylene-dioxythiophene, PEODT). Synthesis-wise, however, the steps necessary in order to obtain such a structure are quite complex. In a first step, polystyrene sphere colloidal crystals were prepared in order to form a template for further reaction. Then $\mathrm{FeF}_{3} \cdot 3 \mathrm{H}_{2} \mathrm{O}$ was obtained through the well-known precipitation synthesis involving $\mathrm{FeCl}_{3}, \mathrm{NaOH}$ and $\mathrm{HF}$ in water. In this particular case, the fluoride was purified by freeze drying. In the next step, iron fluoride colloidal suspension in methanol-water (90:10 vol \%) was prepared. To the suspension were added polystyrene beads as templating agent (1-2 h). After drying, soaking in toluene $(12 \mathrm{~h})$ to remove the polystyrene template, and heat treatment in order to dehydrate the $\mathrm{FeF}_{3} \cdot 3 \mathrm{H}_{2} \mathrm{O}\left(140{ }^{\circ} \mathrm{C}, \mathrm{Ar}\right.$, $15 \mathrm{~h})$ a porous three-dimensionally ordered iron fluoride structure was obtained. Finally, an ethanolic solution of lithium bis(trifluoromethanesulfonyl)imide (LiTFSI), 3,4ethylenedioxythiophene (EDOT) and $3 \mathrm{DOM} \mathrm{FeF}_{3}$ structure was heated at $60{ }^{\circ} \mathrm{C}$ for $2 \mathrm{~h}$. This results in the polymer coating of the fluoride nanostructure (Fig. 7a) via the in situ polymerization of EODT through the reaction:
$\mathrm{FeF}_{3}+\mathrm{LiTFSI}+\mathrm{EODT} \rightarrow \mathrm{LiFeF}_{3}+$ PEODT

While FT-IR spectroscopy provides a clear evidence of the PEODT formation, there is no certainty about the lithiation of iron fluoride since the product appears to be amorphous to XRD. Moreover, if Li was already present in the structure (Eq. 3), the material could start its electrochemical cycling with a charge step, however, this has not been tested. The electrochemical response in the 4.5-1.5 $\mathrm{V}$ versus $\mathrm{Li}^{+} / \mathrm{Li}$ window demonstrates that the 3D architecture is capable of delivering $540 \mathrm{mAh} \mathrm{g}^{-1}$ at the 1st cycle $\left(0.07{ }^{\circ} \mathrm{C}\right.$ rate) with galvanostatic cycles typical of iron fluoride, i.e., a sloping curve at around $3 \mathrm{~V}$ followed by a long plateau at around $1.6 \mathrm{~V}$. Unfortunately, the authors do not concentrate on this enlarged potential window, but instead chose to analyze only the insertion part of the reaction in the $4.5-2 \mathrm{~V}$ versus $\mathrm{Li}^{+} / \mathrm{Li}$ potential window. The material delivers a stable $200 \mathrm{mAh} \mathrm{g}^{-1}$ for 30 cycles at a low rate of $0.03{ }^{\circ} \mathrm{C}$. More interestingly, at high rate $\left(1.4^{\circ} \mathrm{C}\right)$ it delivers $100 \mathrm{mAh} \mathrm{g}^{-1}$ for 100 cycles rate (Fig. 8b). This demonstrates that the structuration plays undeniably a key role in the cycling of iron fluoridebased materials.

Impregnation of ordered mesoporous carbon (OMC) was employed by Jung et al. [63]. The initial $\mathrm{FeCl}_{3} / \mathrm{HF}$ water solution was added, dropwise and for several times, onto OMC with a following drying process $\left(80{ }^{\circ} \mathrm{C}\right.$ under vacuum). Calcination $\left(200^{\circ} \mathrm{C}\right.$, for $36 \mathrm{~h}$ under $\left.\mathrm{Ar}\right)$ yielded the final composite material. XRD results evidence the formation of pure $\mathrm{ReO}_{3}$-type $\mathrm{FeF}_{3}$ with trace amounts of $\mathrm{FeF}_{3} \cdot 0.33 \mathrm{H}_{2} \mathrm{O}$. Moreover, because of capillary diffusion during synthesis, most of the fluoride particles appear to be on the inside of the OMC pores rather than being formed onto the external surface (Fig. 9). From the electrochemistry point of view, the authors also choose to analyze only the insertion part of the reaction taking place in the 4.5-2 $\mathrm{V}$ versus $\mathrm{Li}^{+} / \mathrm{Li}$ window. The main advantage of a carbonaceous-based structuring agent is the certain 


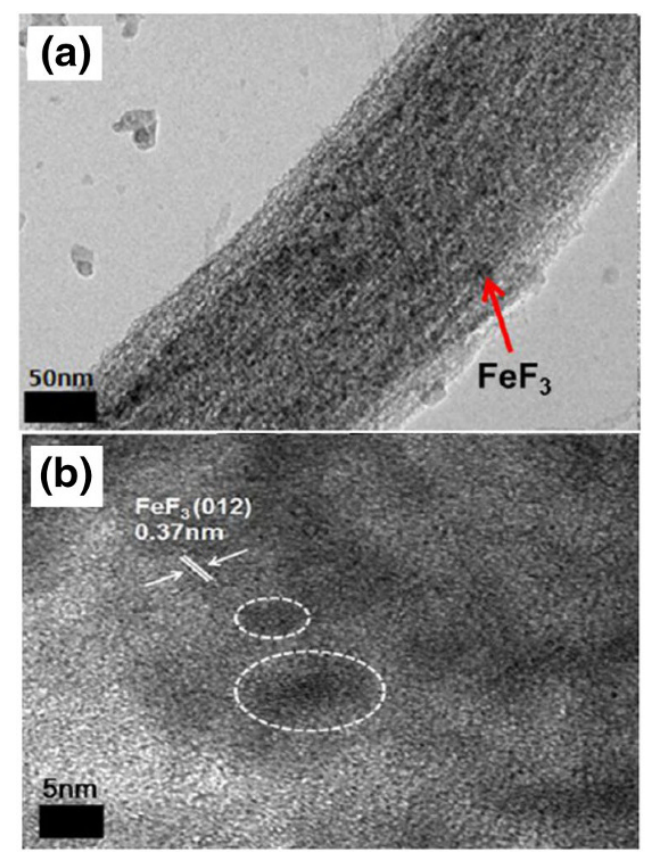

Fig. 9 TEM image of the fluoride/OMC composite (a) and an enlargement on a fluoride particle (b) along with its cycling behavior at various $\mathrm{C}$ rates $(\mathbf{c})$. The composite described in this review is

increase in electronic conductivity, which permits delivering $70 \mathrm{mAh} \mathrm{g}^{-1}$ at $10{ }^{\circ} \mathrm{C}$ rate. On the other hand, the high rate achieved could also be attributed to the HTB-type fluoride that has been demonstrated to easily sustain fast rates in respect to the other iron fluoride phases [35].

Among carbon additives, excluding the already mentioned carbon nanotubes, graphene/graphene oxide and ordered mesoporous carbon, activated carbon microbead $(\mathrm{ACMB})$ can be also used as a structuring agent [64]. After the synthesis of ACMB from glucose, the composite material was obtained via a CTAB-assisted precipitation synthesis: a CTAB-FeCl 3 mixed water solution was slowly added to an ACMB-HF water solution and stirred for $24 \mathrm{~h}$ at RT. The obtained material was then heat-treated at $170{ }^{\circ} \mathrm{C}$ for $10 \mathrm{~min}$, Ar atmosphere. The resulting composite is constituted of a mixture of $\mathrm{FeF}_{3} \cdot 3 \mathrm{H}_{2} \mathrm{O}$ and HTB$\mathrm{FeF}_{3} \cdot 0.33 \mathrm{H}_{2} \mathrm{O}$ which seems to be grafted at the surface of ACMB spherules (about $30 \mu \mathrm{m}$ in diameter) thus keeping the spherical morphology. The authors do not show wide area SEM images, so it is impossible to appreciate how homogeneous the coverage is, also taking into account the small initial amount of ACMB ( 2 wt $\%$ in respect to the overall fluoride quantity). The delivered capacity in the 4.5-2 $\mathrm{V}$ versus $\mathrm{Li}^{+} / \mathrm{Li}$ window was slightly lower than the theoretical $150 \mathrm{mAh} \mathrm{g}^{-1}$ with a stabilization at around $120 \mathrm{mAh} \mathrm{g}^{-1}$ after 50 cycles (at $0.1^{\circ} \mathrm{C}$ rate).

As it has been pointed out in "Simple heat treatment for water removal", surfactants are employed in order to limit particle growth and aggregation and, among them, the most c)

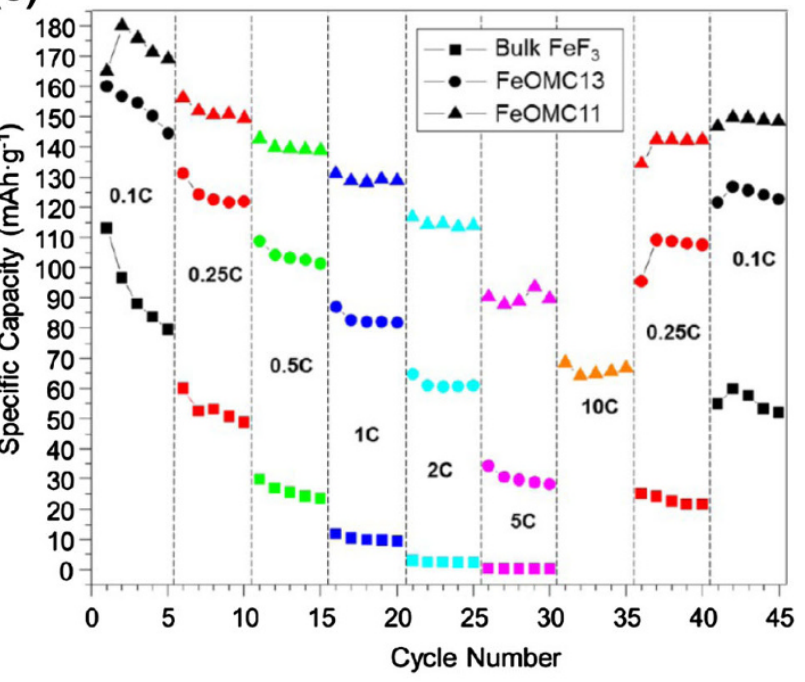

labeled FeOMC11 (triangles). Voltage window $4.5-2 \mathrm{~V}$ vs. $\mathrm{Li}^{+} / \mathrm{Li}$. Adapted with permission from Ref [63]. Copyright 2013, American Chemical Society

employed in iron fluoride synthesis is CTAB. However, the molecule itself can be also employed as a structuring agent directing the assembly of the particles. In the study of Tan et al. [65], CTAB was dissolved with $\mathrm{Fe}\left(\mathrm{NO}_{3}\right)_{3} \cdot 9 \mathrm{H}_{2} \mathrm{O}$ in an ethanol/HF mixed solution and solvothermally treated for $2 \mathrm{~h}$ at $80{ }^{\circ} \mathrm{C}$. The obtained precipitate was then washed and dried at $180{ }^{\circ} \mathrm{C}$ for $12 \mathrm{~h}$. The resulting product, a mixture of $\mathrm{FeF}_{3} \cdot 3 \mathrm{H}_{2} \mathrm{O}$ and $\mathrm{HTB}-\mathrm{FeF}_{3} \cdot 0.33 \mathrm{H}_{2} \mathrm{O}$, consists of quite uniform prismatic/cylindric hollow rods around $3 \mu \mathrm{m}$ long and $500 \mathrm{~nm}$ thick. Unfortunately, the bare structures were not able to meet the requirement of prolonged cycling with a marked capacity fade after 20 cycles $\left(4.5-2 \mathrm{~V} \mathrm{vs.} \mathrm{Li}^{+} / \mathrm{Li}\right.$ at $0.5{ }^{\circ} \mathrm{C}$ rate) and so a ball-milling treatment with acetylene black was carried out. The treatment completely destroyed the hollow structures and lead to small particles intimately mixed with the carbonaceous additive with a consequently ameliorated electrochemical response ( $150 \mathrm{mAh} \mathrm{g}^{-1}$ after 100 cycles in the $4.5-2 \mathrm{~V}$ vs. $\mathrm{Li}^{+} / \mathrm{Li}$ voltage window at $0.5{ }^{\circ} \mathrm{C}$ rate) but effectively eliminating every effort initially put into the formation of self-assembled coherent structures.

Another concept has been investigated by Martha et al. [66] who approached structuration from the point of view of electrode preparation instead of synthesis. The generally accepted method consists of pasting an electrode slurry (active material/carbonaceous additive and plasticizer) onto aluminum foils. Instead of $\mathrm{Al}$, the authors used nongraphitic carbon fibers as current collectors and petroleum pitch as a binding agent between iron fluoride and the 
fibers, thus eliminating the need of an inactive plasticizer (providing only dead weight to the final electrode). After ball milling of commercial $\mathrm{FeF}_{3}$ and a graphene-based electron conductor, the composite powder was mixed with petroleum pitch and the resulting slurry was coated onto the carbon fibers. The electrodes were then directly used after carbonization (around $450{ }^{\circ} \mathrm{C}, 5 \mathrm{~h}$ under Ar). In the voltage window, $4.5-1 \mathrm{~V}$ versus $\mathrm{Li}^{+} / \mathrm{Li}, 600 \mathrm{mAh} \mathrm{g}^{-1}$ have been recorded for the composite at low current density $\left(0.05{ }^{\circ} \mathrm{C}\right.$ rate $)$ with good performances also retained at $1{ }^{\circ} \mathrm{C}$ rate (a stable $400 \mathrm{mAh} \mathrm{g}^{-1}$ for 10 cycles). Moreover, it is noteworthy that the replacement of aluminum by carbon fibers contributes to further reduce the weight of the electrodes permitting higher overall energy per weight unit and thus highlighting the interest of such a technological approach.

\section{Thin films}

The current, rechargeable battery technology implies the use of a liquid electrolyte, which needs to be imbibed into a separator. This characteristic brings to the commercial models several restrictions in terms of design, size and leak-proof assembly. In recent years, the concept of allsolid-state (micro)batteries has found large support from the scientific community due to the increased flexibility of the design of stand-alone microelectronic devices and the enhanced applicability brought by the complete absence of leakage (for example medical implants would be much safer than what they are today) [67]. In order to advance on such a concept, it is very important to be able to produce thin, homogeneous films of active material/separator so that miniaturization is possible without losing the advantages of energy densities and cycle life, which are now achieved by Li-ion cells.

Unlike the extensive work conducted on oxides and phosphates [67, 68], only few works have been published on iron fluoride thin films applied to Li-ion batteries. In one of them, Makimura et al. $[69,70]$ used pulsed laser deposition (PLD) to grow iron fluoride thin films from 80 to $150 \mathrm{~nm}$ in thickness. The technique consists in pulsing a laser source with a $2 \mathrm{~Hz}$ frequency onto $\mathrm{FeF}_{3}$ or $\mathrm{FeF}_{2}$ target. The target is then vaporized creating a thin film on a stainless steel substrate. Typical electrochemical curves for $\mathrm{FeF}_{2}$ samples deposited at the high $\mathrm{T}\left(600{ }^{\circ} \mathrm{C}\right)$ and $\mathrm{RT}$ are recorded. All the reported films presented a very large reversible over-capacity at low potentials (between 1 and $0.05 \mathrm{~V} \mathrm{vs}$. $\mathrm{Li}^{+} / \mathrm{Li}$ ) acting as the main electrochemical phenomenon and granting the very interesting performances reported (around $500 \mathrm{mAh} \mathrm{g}^{-1}$ for 20 cycles). Such a behavior has been explained as an interfacial interaction of lithium within the $\mathrm{Fe} / \mathrm{LiF}$ matrix leading to local charging (interfacial storage).
More recently, direct formation of a fluoride-based layer has also been achieved by electrodeposition. Guitian et al. [71] anodized iron strips in an ethylene glycol/water $\mathrm{NH}_{4} \mathrm{~F}$ electrolyte with a potential of $50 \mathrm{~V}$ for duration of $15 \mathrm{~min}$. The resulting electrodes are formed of a highly porous layer (Fig. 10) constituted by a mixture of iron oxy-/ hydroxy-fluorides. The electrochemical curve shows many features correlated to the various fluoride species and, in particular to $\mathrm{FeO}_{\mathrm{x}} \mathrm{F}_{\mathrm{y}}$ [72]. The more interesting characteristic, however, is the enhanced cyclability of the layer which retains both its overall structure and porosity after 200 cycles.

\section{Prelithiation}

Current, commercial Li-ion technology comprises a carbon-based anode and lithium-containing cathode material. Adopting such a configuration was inevitable after the problems deriving from Li dendritic growth during charge [73]. As such, the first generation $\mathrm{Li} / \mathrm{TiS}_{2}$ cells were replaced by the so-called "rocking chair" systems as we know them nowadays. At the current state of technology, $\mathrm{FeF}_{3}$ suffers from a more debilitating plague than electronic insulation or reaction kinetics: the lack of lithium in the initial material. One way to solve the problem would be the use of prelithiated anodes which are difficult to manufacture and handle in practice. Research is focusing on how to introduce lithium in the structure so as to actually give a chance to fluorides in the next generation of accumulators.

The direct synthesis of the charge end-product (the $\mathrm{Li}_{0.5} \mathrm{FeF}_{3}$ trirutile structure, see "Early research, characteristics and electrochemical mechanism of FeF3") has been reported in 1969 [74]. Through heat treatment at high temperature $\left(1000{ }^{\circ} \mathrm{C}\right)$ of an equimolar mixture of $\mathrm{LiF}$, $\mathrm{FeF}_{2}$ and $\mathrm{FeF}_{3}$ powders, it was possible to obtain the pure $\mathrm{LiFe}_{2} \mathrm{~F}_{6}$ trirutile phase. A successive study pointed out that single-crystals can be obtained through hydrothermal synthesis in fluorolytic medium $\left(5 \mathrm{M} \mathrm{HF}\right.$ solution at $650{ }^{\circ} \mathrm{C}$ ) starting from $\mathrm{LiF}$ and $\mathrm{FeF}_{3}$ [75]. A more recent study, however, introduces the possibility of mechanical milling of the same equimolar mixture of fluorides although the process requires very high milling times $(40 \mathrm{~h}$ for the initial product and another hour after addition of carbon black) $[76,77]$. The pure product showed a poor intercalation behavior (less than $120 \mathrm{mAh} \mathrm{g}^{-1}$ after 15 cycles in the $4.5-2 \mathrm{~V}$ vs. $\mathrm{Li}^{+} / \mathrm{Li}$ voltage window at $0.08 \mathrm{C}$ rate) which could be ameliorated when the synthesis was conducted with a slight excess of lithium $\left(\mathrm{Li}_{1.2} \mathrm{Fe}_{2} \mathrm{~F}_{6.2}\right)$. Mößbauer spectroscopy pointed out that the mechanical treatment is rough enough to promote loss of fluorine, resulting in an under stoichiometric compound bearing a 

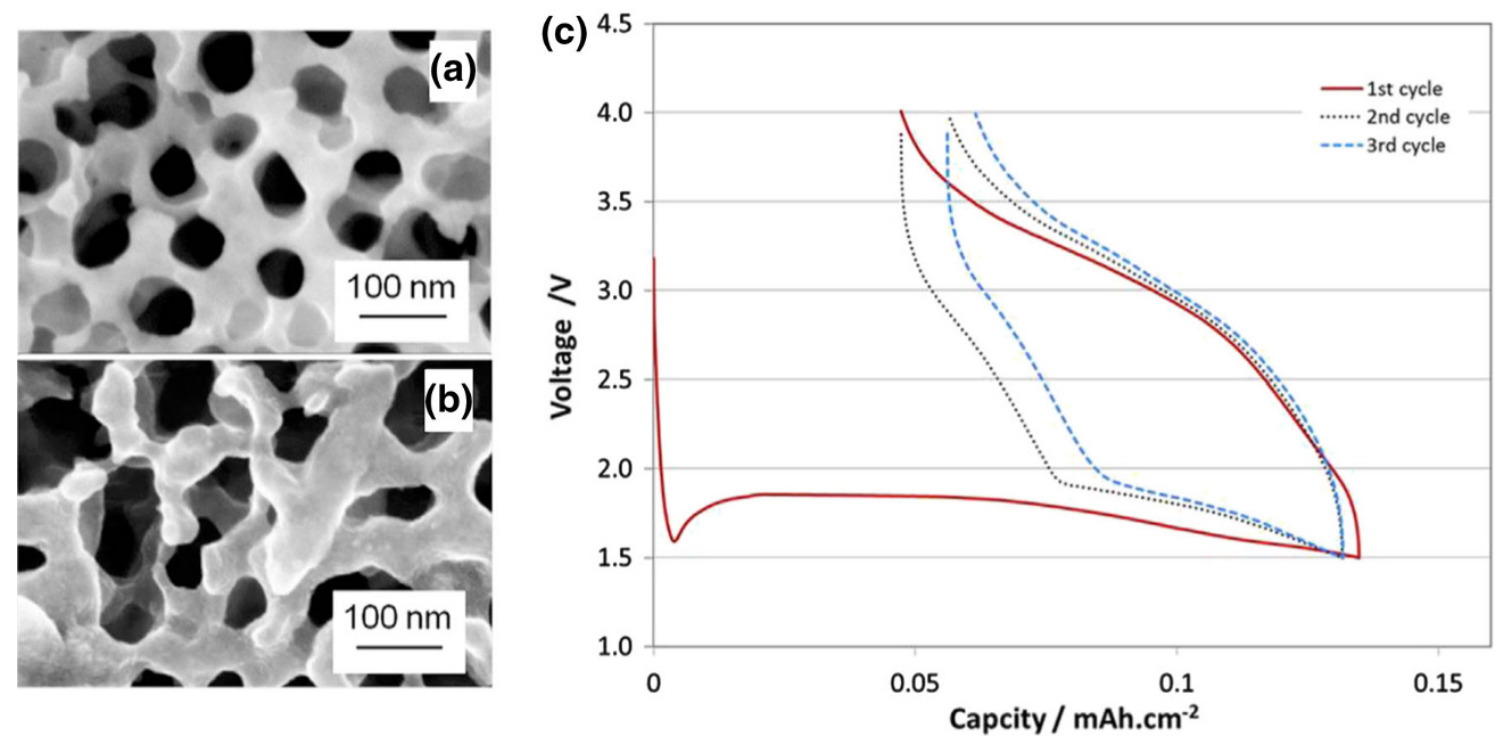

Fig. $10 \mathrm{SEM}$ images of the oxy-/hydroxy-fluoride layer obtained at $50 \mathrm{~V}$ before (a) and after (b) $200 \mathrm{cycles}\left(4-1.5 \mathrm{vs} . \mathrm{Li}^{+} / \mathrm{Li}^{\text {at }} 30 \mu \mathrm{A} \mathrm{cm}{ }^{-2}\right)$. The first few galvanostatic cycles are reported in (c). Figure adapted form Ref [71]. Copyright 2013, with permission from Elsevier

large number of anionic vacancies. Thus, the authors ascribe the ameliorated electrochemical performance (around $140 \mathrm{mAh} \mathrm{g}^{-1}$ after 30 cycles in the 4.5-2 V vs. $\mathrm{Li}^{+} / \mathrm{Li}$ voltage window at $0.08{ }^{\circ} \mathrm{C}$ rate) to the vacancy effect over structural order.

Since the trirutile $\mathrm{Li}_{0.5} \mathrm{FeF}_{3}$ requires both harsh conditions for its synthesis and some defective structure in order to work properly, other approaches are being explored with the aim of producing a prelithiated fluoride cathode. The most direct approach consists in obtaining the end products of the conversion reaction, $\mathrm{LiF}$ and $\mathrm{Fe}$ (see Eq. 2), as an intimate mix.

The first exploration of the concept was performed by Amatucci around 2004 and later in 2011 [78, 79]. Prelithiation was achieved through a solid state route involving high-energy milling of $\mathrm{Li}_{3} \mathrm{~N}, \mathrm{FeF}_{3}$ and carbon powders. For the sake of comparison, the same technique was employed also for $\mathrm{BiF}_{3}$ and $\mathrm{FeF}_{2}$. The choice of reactants lies at the base of the following reaction (Eq. 4):

$\mathrm{Li}_{3} \mathrm{~N}+\mathrm{FeF}_{3} \rightarrow 3 \mathrm{LiF}+\mathrm{Fe}+1 / 2 \mathrm{~N}_{2}$

Even if the theoretical reaction can seem simple, the authors showed that the final products have a deep dependency on the $\mathrm{Li}_{3} \mathrm{~N}$ to $\mathrm{FeF}_{3}$ initial ratio. Although the reaction seems to proceed as expected for the stoichiometric 1:1 ratio, a wide variety of products can be obtained for a lower or higher amount of nitride. For amounts of $\mathrm{Li}_{3} \mathrm{~N}$ up to $0.5 \mathrm{Li}$, a rutile-like phase can be obtained which cannot, however, be identified as $\mathrm{Li}_{0.5} \mathrm{FeF}_{3}$. For higher amounts up to $1 \mathrm{Li}, \mathrm{Li}_{3} \mathrm{FeF}_{6}$ and $\mathrm{Fe}$ are formed, while for even higher amounts (above the 1:1 ratio), various iron nitride phases were also observed. The Bi-based composites showed a more satisfactory electrochemistry than the Fe-based ones for two main reasons: on the one hand, during the mechanotreatment there can be formation of $\mathrm{Li}_{x} \mathrm{Bi}$ alloys, which can help the diffusivity of Li into the resulting particles, while $\mathrm{Fe}$ does not produce any alloy with $\mathrm{Li}$. On the other hand, iron fluorides have a greater sensitivity to crystallite size due to their slower kinetics in respect to $\mathrm{BiF}_{3}$ and the mechanotreatment was able to produce particles of roughly $10 \mathrm{~nm}$ for the Fe-based products, while half that size was detected for the Bi-based product.

Based on the above results, Liao et al. [80, 81] used magnetron co-sputtering to create a 64-sample library of $\mathrm{LiF}_{(1-x)} / \mathrm{Fe}_{x}(0<x<1)$ compositions. The principle of the experiment was to rapidly examine a series of possible compositions in order to quantify the optimal $\mathrm{LiF} / \mathrm{Fe}$ ratio for an acceptable electrochemical result. Without surprise, the best performances were obtained when the ratio of $\mathrm{LiF} /$ Fe was $3 / 1$ but the interesting result turned out to be a confirmation of the appearance of interfacial storage (see previous section) for cutoff voltages of $1.2 \mathrm{~V}$ versus $\mathrm{Li}^{+} /$ Li. In fact, co-deposited $\mathrm{LiF} / \mathrm{Fe}$ thin layers already possess an interfacial region between $\mathrm{LiF}$ domains and $\mathrm{Fe}$ domains that enables overcapacity. Moreover, by Mößbauer spectroscopy, the 'excess' of $\mathrm{Li}$ ions could be univocally proved to be located at the $\mathrm{LiF}$ side of the interface with the corresponding electrons enriching the $\mathrm{Fe}$ side as a consequence.

Further ball milling techniques were then carried directly on the $\mathrm{LiF} / \mathrm{Fe} 3 / 1$ ratio. Li et al. [82] used a twostep milling adding to the commercial LiF and iron powders a nanometric TiN. In the second step, further milling 
was conducted on the $\mathrm{LiF} / \mathrm{Fe} / \mathrm{TiN}$ with addition of graphite. Instead of promoting the formation of $\mathrm{LiF}$ with release of a gas, as described in the work of Amatucci (Eq. 4), here the TiN nanoparticles act as both a grinding-enhancer powder and as a structuring agent forming a conductive nanometric core capable of fixing the electroactive components in order to prevent phase segregation and/or aggregation. Electrodes were prepared with the customary addition of conductive agent and plasticizer (10 wt \% each) and good performances were recorded in the enlarged potential window 4.5-1 $\mathrm{V}$ versus $\mathrm{Li}^{+} / \mathrm{Li}$ with around $300 \mathrm{mAh} \mathrm{g}$ for 20 cycles at $0.7{ }^{\circ} \mathrm{C}$ rate.

A third approach, explored by Kim et al. [83], consists not in the direct milling of the end products of the conversion reaction (such as $\mathrm{LiF} / \mathrm{Fe}$ in the $3 / 1$ ratio, see Eq. 2) but in mimicking the composition at the end of the insertion reaction (such as $\mathrm{LiF} / \mathrm{FeF}_{2}$ in the $1 / 1$ ratio, see Eq. 1). A two-step milling was again used, first adding $\mathrm{FeF}_{2}$ to $\mathrm{LiF}$ (both commercial powders) and then further milling after addition of graphite. Electrodes were prepared by slurry (20 wt \% of conductive agent and $10 \mathrm{wt} \%$ of plasticizer) and around $200 \mathrm{mAh} \mathrm{g}^{-1}$ were delivered in the potential window $4.8-2 \mathrm{~V}$ versus $\mathrm{Li}^{+} / \mathrm{Li}$. The interesting point here is the peculiar reaction of the $\mathrm{FeF}_{2}-\mathrm{LiF}$ composite which, although similar in composition to the electrochemically formed $\mathrm{LiFeF}_{3}$, reacts via a different pathway. With the help of X-ray absorption fine structure and near edge structure (EXAFS/XANES), XPS and DRX studies, the authors were able to prove that, during the first charge, the excess of fluorine resulting from $\mathrm{Li}^{+}$release, would be incorporated into the remaining $\mathrm{FeF}_{2}$ to form a higher oxidation state fluoride analogous to $\mathrm{ReO}_{3}$-type $\mathrm{FeF}_{3}$ although highly defective. The following reaction would follow the scheme reported in Eq. 1 with an insertion inside the newly formed iron trifluoride.

Ma et al. [84] produced a composite starting from hydrothermally synthesized $\mathrm{Fe}_{3} \mathrm{O}_{4}$ /reduced graphene oxide ball-milled with $\mathrm{LiF}$. The resulting $\mathrm{LiF} / \mathrm{Fe}_{3} \mathrm{O}_{4} /$ reduced graphene oxide powder was then heat-treated in a reducing environment $\left(550^{\circ} \mathrm{C}, 4 \mathrm{~h}, \mathrm{Ar} / \mathrm{H}_{2}\right)$. After the heat treatment, TEM images reveal that magnetite is successfully reduced to $\alpha$-Fe particles $(50-60 \mathrm{~nm})$, grafted onto the reduced graphene oxide surface. At the same time, while no evolution of average particle size is recorded for $\mathrm{LiF}$ $(100-150 \mathrm{~nm})$, the particles do not seem to be well homogenized with iron, and large void spaces can be observed. However, a good cycling stability with a certain decrease in polarization can be observed in the potential window $4.5-1.5 \mathrm{~V}$ versus $\mathrm{Li}^{+} / \mathrm{Li} \quad\left(0.03-0.14{ }^{\circ} \mathrm{C}\right.$ rates $)$ certainly due to the benefic effect of the conductive reduced graphene oxide layers.

The synthetic method employed by Prosini et al. [85] sits in the midway between the formation of $\mathrm{LiF}$ with release of a gas proposed by Amatucci's group (Eq. 4) and the previously illustrated oxide reduction to obtain $\mathrm{Fe}^{0}$. In their study, a mixture of hematite and lithium hydride was placed in an oven at $700{ }^{\circ} \mathrm{C}$ for $1 \mathrm{~h}$ in $\mathrm{N}_{2} / \mathrm{H}_{2}$ flow to obtain a $\mathrm{Fe} / \mathrm{Li}_{2} \mathrm{O}$ composite. A second heat treatment in the presence of $\mathrm{NH}_{4} \mathrm{~F}\left(500{ }^{\circ} \mathrm{C}\right.$ for $\left.1 \mathrm{~h}, \mathrm{~N}_{2} / \mathrm{H}_{2}\right)$ transformed the $\mathrm{Fe} /$ $\mathrm{Li}_{2} \mathrm{O}$ composite into a $\mathrm{Fe} / \mathrm{LiF}$ composite. Overall, the following reactions occur (Eqs. 5, 6):

$$
\begin{aligned}
6 \mathrm{LiH}+\mathrm{Fe}_{2} \mathrm{O}_{3} \rightarrow 3 \mathrm{Li}_{2} \mathrm{O}+ & 2 \mathrm{Fe}+3 \mathrm{H}_{2} \\
3 \mathrm{Li}_{2} \mathrm{O}+2 \mathrm{Fe}+6 \mathrm{NH}_{4} \mathrm{~F} \rightarrow & 6 \mathrm{LiF}+2 \mathrm{Fe}+6 \mathrm{NH}_{3} \\
& +3 \mathrm{H}_{2} \mathrm{O}
\end{aligned}
$$

The synthesis does not seem to be optimized at the moment as $\mathrm{FeF}_{2}$ and $\mathrm{Li}_{5} \mathrm{FeO}_{4}$ impurities have been detected by XRD; morphology is also an issue as the high temperatures favor particle coalescence and growing deeply affecting the electrochemical results.

An original approach was published by Prakash et al. $[86,87]$ in which carbon nanotubes and other carbon-based structures were directly grown on a $\mathrm{LiF} / \mathrm{Fe}$ composite by decomposition of ferrocene deriving from a dried dispersion with $\mathrm{LiF}$ in diethyl ether. The resulting powders were sealed (under Ar) into a specially designed stainless steel/ quartz rotating reactor and heated at $700{ }^{\circ} \mathrm{C}\left(35^{\circ} \mathrm{C} \mathrm{min}{ }^{-1}\right.$, $10 \mathrm{rpm}$ for $5 \mathrm{~h}$ ). The concept behind this procedure is that the iron produced from the ferrocene decomposition, will act as catalyst for the growth of nanotubes and core-shell structures deriving from various carbon-based reactive gases (Fig. 11a, b).

In addition to the $\mathrm{LiF} / \mathrm{Fe} / \mathrm{C}$ composite, however, iron carbide $\left(\mathrm{Fe}_{3} \mathrm{C}\right)$ was also obtained as a result of the deactivation of the $\mathrm{Fe}$ catalyst. Electrochemistry studies showed very encouraging results with a stable capacity of $220 \mathrm{mAh} \mathrm{g}^{-1}$ for 150 cycles in the broad electrochemical window $4.5-1.3 \mathrm{~V}$ versus $\mathrm{Li}^{+} / \mathrm{Li}$, but at a low current density of $0.03{ }^{\circ} \mathrm{C}$. It is noteworthy that the reported electrodes were used as pure powders without further additives (carbon black or PVdF binder) and that the remarkable properties could be related to the high amount of carbon (around $45 \mathrm{wt} \%$ from elemental analysis) unfortunately, the inactive iron carbide contributes to some hindering of the electrochemical performance due to the consumption of iron.

Another ferrocene-based synthesis was recently introduced by Zhang et al. [88]. The authors produced fibers from electrospun solutions of $\mathrm{LiF}$, ferrocene and polyacrylonitrile (PAN) which were then heat-treated in two steps: a first annealing at $280{ }^{\circ} \mathrm{C}$ in air for $5 \mathrm{~h}$ followed by a carbonization at $900{ }^{\circ} \mathrm{C}(8 \mathrm{~h}$ under $\mathrm{Ar})$. The resulting composite yielded freestanding and flexible electrodes with some degrees of 3D structuration. Electrochemical tests were conducted in the window $4.2-0.5 \mathrm{~V}$ versus $\mathrm{Li}^{+} / \mathrm{Li}$ 

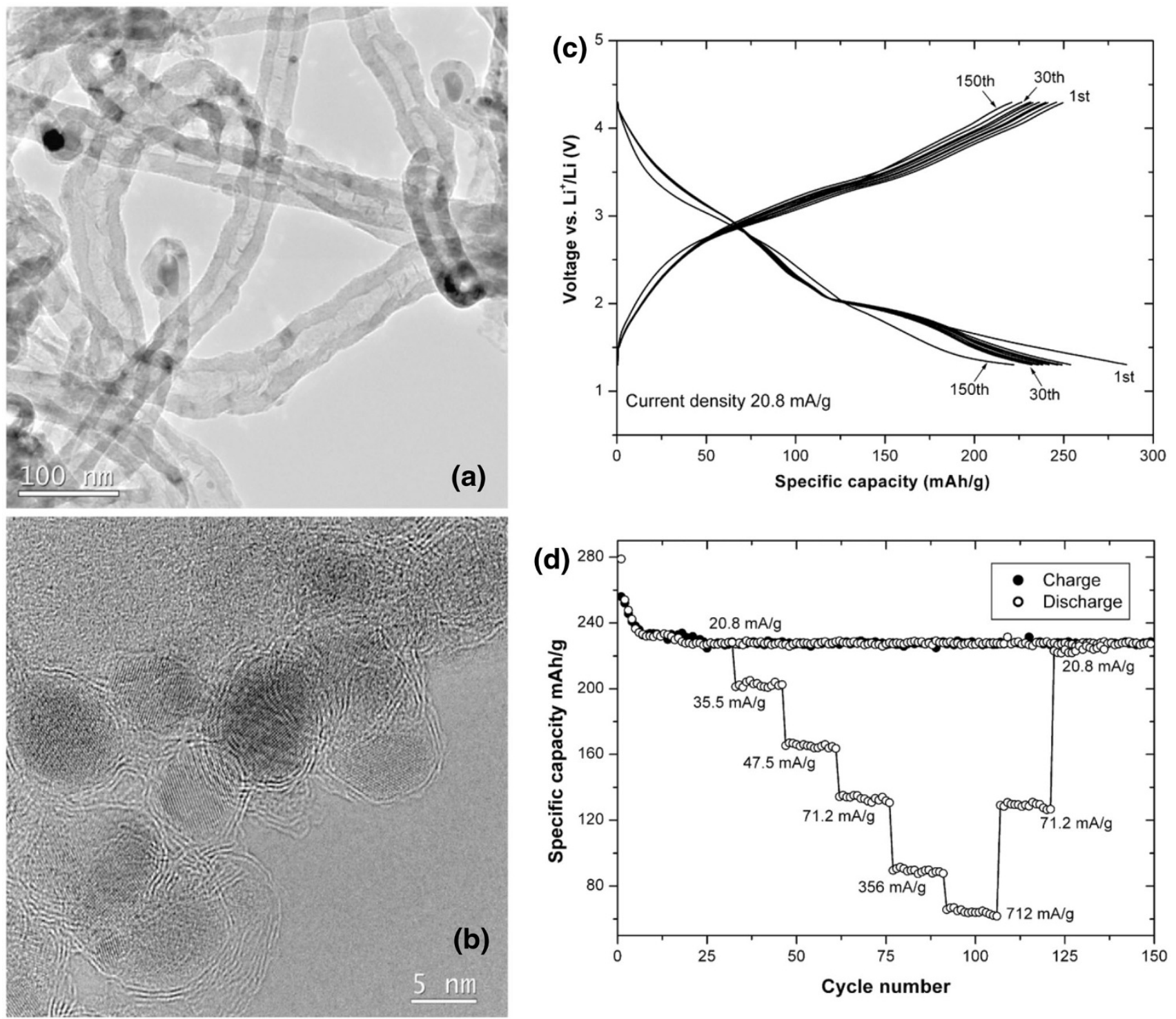

Fig. 11 TEM images of the structures obtained from the ferrocenebased reaction: nanotubes with encapsulated iron particles (a) and onion-like coating of iron particles (b). Galvanostatic cycles are

resulting in around $400 \mathrm{mAh} \cdot \mathrm{g}^{-1}$ delivered after 50 cycles (current density of $0.05{ }^{\circ} \mathrm{C}$ ) even if a marked tendency to performance degradation can be observed after the 30th cycle.

\section{Other derivatives}

Other iron fluoride compounds could be employed for the development of cathodic materials for the next generation of accumulators. It is the case of lithium fluoroferrate or sodium-iron fluorides which can open new perspectives for the research and development sectors. reported in (c) while the cycling behavior at various $\mathrm{C}$ rates is shown in (d). Voltage window: 4.5-1.3 vs. $\mathrm{Li}^{+} / \mathrm{Li}$. Adapted from Ref [87]. Copyright 2011, with permission from Elsevier

\section{Lithium fluoroferrate}

Lithium fluoroferrate $\left(\mathrm{Li}_{3} \mathrm{FeF}_{6}\right)$ possesses two polymorphs (monoclinic $\alpha$-phase and orthorhombic $\beta$-phase) with structures closely related to cryolite $\left(\mathrm{Na}_{3} \mathrm{AlF}_{6}\right)$. Both structures consist of isolated and slightly distorted $\mathrm{FeF}_{6}$ octahedra which under tilt rotation produce either one or the other polymorph. These octahedra are linked together by interconnected lithium polyhedra in the tri-dimensional structure. The most active group on the electrochemical study of this compound is that of Garcia-Alvarado [89-92] who deeply studied the behavior of both phases. They found a better activity of the $\alpha$-polymorphin in respect to 
the $\beta$-form and a correlation between particle size and delivered capacity. As a general remark, the $\alpha$-polymorph can be obtained with smaller particle size, and the synthesis was optimized until the full theoretical capacity was obtained $\left(140 \mathrm{mAh} \mathrm{g}^{-1}\right)$. This optimized synthesis involves stoichiometric amounts of reagents $\left(\mathrm{Fe}\left(\mathrm{NO}_{3}\right)_{3} \cdot 9 \mathrm{H}_{2} \mathrm{O}\right.$, $\mathrm{HF}$ water solution and $\left.\mathrm{Li}_{2} \mathrm{CO}_{3}\right)$, which lead to the precipitated fluoroferrate product after addition of 2-propanol at $0{ }^{\circ} \mathrm{C}$. A further ball milling treatment $(12 \mathrm{~h})$ yielded the final fluoride/carbon composite. The composite material obtained by this synthetic route was able to deliver $140 \mathrm{mAh} \mathrm{g}^{-1}$ in the voltage window 4.5-2.25 V versus $\mathrm{Li}^{+} / \mathrm{Li}$ at $0.06{ }^{\circ} \mathrm{C}$ rate. More recently [92], simulations pointed out that defects are energetically favoured especially for small crystallites with the most probable defect types being Li-excess (with consequent local reduction of $\mathrm{Fe}^{\mathrm{III}}$ to $\mathrm{Fe}^{\mathrm{II}}$ ) and/or Frenkel defects (lithium insertion into interstitial sites). Moreover, lithiumion transport in $\mathrm{Li}_{3} \mathrm{FeF}_{6}$ seems to be closely related to interstitial migration (low calculated activation energies of $0.4 \mathrm{eV}$ ) paving the way for a doping strategy consisting in the introduction of different ions into iron sites, such as divalent $\mathrm{Ni}, \mathrm{Mg}$, Co or $\mathrm{Mn}$, to promote $\mathrm{Li}$ interstitial compensation.

At the current state, however, the fluoroferrate cannot represent a viable electrode material due the low capacity associated with a $1 \mathrm{e}^{-}$reaction and to problems in lithium extraction. In fact, the charge reaction of $\mathrm{Li}_{3} \mathrm{FeF}_{6}$ involves $\mathrm{Fe}^{\mathrm{IV}}$ metal centers and, even if it has been recently calculated that $\mathrm{Li}_{2} \mathrm{FeF}_{6}$ is a stable compound, there is currently no experimental observation for the latter also due to the prohibitive reaction potential of $6.1 \mathrm{~V}$ versus $\mathrm{Li}^{+} / \mathrm{Li}$ [93].

Sodium-iron fluorides $\left(\mathrm{NaFeF}_{3}\right.$ and $\left.\mathrm{Na}_{3} \mathrm{FeF}_{6}\right)$

Sodium-ion batteries have recently drawn the attention of the scientific community as low cost and low environmental impact devices with widely available starting materials and low toxicity [94]. As it has been highlighted in previous sections, some iron fluorides have found an application also in Na-ion cells; one example is the HTB$\mathrm{FeF}_{3} \cdot 0.33 \mathrm{H}_{2} \mathrm{O}$ structure. As it concerns the $\mathrm{ReO}_{3}$-type $\mathrm{FeF}_{3}$, its structure has the potential to accommodate also Na-ions during the intercalation reaction (Eq. 1) although with slower kinetics than Li-ions [95]. In the case of sodium, however, the intermediate $\mathrm{NaFeF}_{3}$ is well known and can be easily synthesized. Although technically not a $\mathrm{Fe}^{\mathrm{III}}$ compound, $\mathrm{NaFeF}_{3}$ finds easily its place in this review due to the concept it represents. There is not much research concerning this material [96-98]. An optimized synthesis method, based on the observation that capacity increases with the crystallinity of the final $\mathrm{NaFeF}_{3}$ compound, involves a stoichiometric mixture of $\mathrm{FeF}_{2}$ and $\mathrm{NaHF}_{2}$. The reagents are then submitted to a roll-quenching technique where the melt obtained by heating at $1,000{ }^{\circ} \mathrm{C}$ ( $40 \mathrm{~s}$ under $\mathrm{Ar})$ is injected into a fast spinning copper roller $(2,000 \mathrm{rpm})$. Ball-milling with acetylene black provides the final composite material which can deliver the full capacity associated with the $1 \mathrm{e}^{-}$reaction $\left(200 \mathrm{mAh} \mathrm{g}^{-1}\right.$ at $0.014{ }^{\circ} \mathrm{C}$ rate in the potential window $4.5-1.5 \mathrm{~V}$ vs. $\mathrm{Na}^{+} /$ $\mathrm{Na}$. A more significative finding was, however, that among the isostructural $\mathrm{NaMF}_{3}$ series (with $\mathrm{M}=\mathrm{Mn}, \mathrm{Fe}$, $\mathrm{Co}$ and $\mathrm{Ni}$ ), $\mathrm{NaFeF}_{3}$ is the only phase capable of reversible $\mathrm{Na}^{+}$deinsertion/insertion. This occurrence finds its explanation mainly in the chemical stability of the de-intercalated fluorides, $\mathrm{MF}_{3}$ (with $\mathrm{M}=\mathrm{Mn}, \mathrm{Co}$ and $\mathrm{Ni}$ ) being known fluorinating agents. Only the affinity of iron toward fluorine ensures the ability of $\mathrm{NaFeF}_{3}$ to sustain cycling.

Yamada et al. [99] prepared dispersed and uniform particles by liquid-phase synthesis involving the thermal decomposition of iron and sodium trifluoroacetates in a mixture of oleic acid and oleylamine (10/10 molar ratio) at $280{ }^{\circ} \mathrm{C}$ for $30 \mathrm{~min}$ under Ar. The resulting particles were mixed with acetylene black by ball milling to yield the final composite material. TEM microscopy studies evidence an average particle size $10-20 \mathrm{~nm}$. The composite delivers $115 \mathrm{mAh} \mathrm{g}^{-1}$ at $1^{\circ} \mathrm{C}$ rate in the potential window $4.5-1.5 \mathrm{~V}$ versus $\mathrm{Na}^{+} / \mathrm{Na}$.

Just like lithium fluoroferrate, the sodium analogue, $\mathrm{Na}_{3} \mathrm{FeF}_{6}$, is related to cryolite structure. Shakoor et al. [100] prepared sodium fluoroferrate through dry ball milling using stoichiometric amounts of sodium and iron fluorides $\left(3 \mathrm{NaF}: 1 \mathrm{FeF}_{3}\right)$. The composite delivers around $110 \mathrm{mAh} \mathrm{g}^{-1}\left(0.1{ }^{\circ} \mathrm{C}\right.$ rate $)$ in the potential window $4.25-0.5 \mathrm{~V}$ versus $\mathrm{Na}^{+} / \mathrm{Na}$, but capacity faded progressively from the 10th cycle on. The probable reason has been identified by the authors in the difficult-to-reverse conversion reaction since $\mathrm{NaF}$ and $\mathrm{Fe}$ have been found in the discharged electrode. As a final remark, unless the same concept of interstitial charge compensation, which has been postulated for the lithium fluoroferrate is also valid for the sodium analogue (see Ref [92]), the charge reaction of $\mathrm{Na}_{3} \mathrm{FeF}_{6}$ to $\mathrm{Na}_{2} \mathrm{FeF}_{6}$ cannot be the initial step, so a hypothetical device would require a discharge step in order to start its operative life.

\section{Conclusions}

Before concluding this review, we would like to present the reader with an overview of the most interesting points the research on iron fluorides applied to batteries has elucidated: 
- Pure $\mathrm{FeF}_{3}$ is highly hygroscopic so that its stability in air at RT is very limited. The compound will accept water molecules producing a series of $\mathrm{H}_{2} \mathrm{O}$-stabilized structures until reaching the $\mathrm{FeF}_{3} \cdot 3 \mathrm{H}_{2} \mathrm{O}$ stoichiometry. This hydration process is fairly common in solutionbased syntheses and generally yields HTB$\mathrm{FeF}_{3} \cdot 0.33 \mathrm{H}_{2} \mathrm{O}$ or pyrochlore- $\mathrm{FeF}_{3} \cdot 0.5 \mathrm{H}_{2} \mathrm{O}$ structures;

- Water molecules act as strong structural stabilizers during the electrochemical lithiation promoting an intercalation behavior in the same potential window where anhydrous $\mathrm{FeF}_{3}$ would react with the full conversion. This occurrence limits the theoretical capacity (150 mAh g ${ }^{-1}$ for $\mathrm{HTB}-\mathrm{FeF}_{3} \cdot 0.33 \mathrm{H}_{2} \mathrm{O}$ instead of $712 \mathrm{mAh} \mathrm{g}^{-1}$ for $\mathrm{FeF}_{3}$ at $1.5 \mathrm{~V}$ vs. $\mathrm{Li}^{+} / \mathrm{Li}$ ) but permits faster $\mathrm{Li}^{+}$diffusion with good capacities retained even at $1 \mathrm{C}$ rates;

- These water molecules can be highly mobile so it is not uncommon to observe loss of structural water resulting in a tendency to steady performance degradation with cycling. One of the possible reasons is that water can hydrolize the $\mathrm{LiPF}_{6}$ salt into $\mathrm{LiOH}, \mathrm{PF}_{5}$ and $\mathrm{HF}$. Therefore, careful structural assessment, coating or other structure stabilization has to be envisaged for such materials;

- When envisaging the production of a water-free $\mathrm{FeF}_{3}$, the effect of the initial $\mathrm{F}^{-}$concentration has to be taken into account. A large excess of $\mathrm{HF}$ compared to $\mathrm{Fe}$, favors the growth of amorphous fluoride wires. The wire morphology favors the formation of contiguous and interconnected $1 \mathrm{D} \mathrm{Fe}$ domains at the end of the conversion reaction potentially paving the way for the full $3 \mathrm{e}^{-}$reaction;

- It is possible to create ordered three-dimensional structures for fluoride-based materials, which would result in ameliorated diffusivity of the electrolyte and possibly in the reduction of the nanoparticles aggregation originating from the conversion reaction [61];

- The absence of preliminary Li content is a major obstacle for the development of fluoride-based cathode materials. Prelithiation is thus a point to extensively study;

- An alternative to prelithiation could be $\mathrm{Li}^{+}$compensation induced by divalent cation doping. This effect has, so far, been predicted only for the $\mathrm{Li}_{3} \mathrm{FeF}_{6}$ compound but it is not impossible that a similar behavior could be induced in structures such as the $\mathrm{HTB}-\mathrm{FeF}_{3} \cdot 0.33 \mathrm{H}_{2} \mathrm{O}$ or pyrochlore- $\mathrm{FeF}_{3} \cdot 0.5 \mathrm{H}_{2} \mathrm{O}$;

- Open structures and certain derivatives also suggest a viable exploration of the sodiation reaction for the development of cheaper cells.

As far as it is possible to observe in the actual state of research, the most promising iron fluoride-based cathodic materials are obviously represented by the hydrated HTB and pyrochlore phases. In fact, it has been widely proven that these two structures are easy enough to synthesize through different soft-chemistry-based techniques using low-cost or reusable starting materials. The main hindrances to the development of these materials are represented by the relatively low capacity $\left(150 \mathrm{mAh} \mathrm{g}^{-1}\right)$, the lower, sloped reaction potential $\left(3.2-3.3 \mathrm{~V}\right.$ vs. $\left.\mathrm{Li}^{+} / \mathrm{Li}\right)$ compared to the higher, flatter potential of, for example, $\mathrm{LiFePO}_{4}\left(3.4 \mathrm{~V}\right.$ vs. $\left.\mathrm{Li}^{+} / \mathrm{Li}\right)$ and the lack of lithium/sodium in the initial compound.

While Fe-based materials offer advantages with respect to environmental and economic considerations, the major difficulty in the electrochemistry of $\mathrm{Fe}$ is the lower voltage obtained when compared to other transition metals such as Co or Ni. A way to overcome this issue was demonstrated in 1989 on a comparative study between the three iron analogues $\mathrm{Fe}_{2}\left(\mathrm{MoO}_{4}\right)_{3}, \mathrm{Fe}_{2}\left(\mathrm{WO}_{4}\right)_{3}$ and $\mathrm{Fe}_{2}\left(\mathrm{SO}_{4}\right)_{3}$ [101]. Since all three compounds possess very similar metaloxygen distances and formal charge, the increased redox potential with lithium from around $3.0 \mathrm{~V}$ for the molybdate and tungstate to $3.6 \mathrm{~V}$ for the sulfate, came as a surprising effect. The "inductive affect", as it became known, was originating from the significantly larger electronegativity of the sulfate groups resulting in an increase of the ionic character of the $\mathrm{Fe}-\mathrm{O}$ bonds. Thus, it is thanks to the inductive effect that sulfide-based electrode materials always display a lower potential than the corresponding oxides, as well as why the fluoride analogues show even higher potentials. In this last case in particular, manipulations axed on the increase of $\mathrm{Fe}-\mathrm{F}$ bond ionic character by replacement of the anion would be complex since fluorine is already the most electronegative element. Instead, one way to act on the iron-fluorine bond could be the application of chemical pressure [102]. When smaller cations are replaced by larger ones in a close-packed structure, the result from the point of view of the smaller ion is comparable to an elongation of the bond thereby increasing its ionic nature. This is why accurate doping with $\mathrm{Co}, \mathrm{Ni}$ or $\mathrm{Cu}$ would probably give some result in this direction.

Both capacity and prelithiation could be ameliorated by the careful application of blending, combining different active materials. Just like spinel/layered mixtures $\left(x \mathrm{Li}_{2} \mathrm{MnO}_{3} \cdot(1-x) \mathrm{LiMO}_{2}\right.$ with $\mathrm{M}=\mathrm{Mn}, \mathrm{Co}, \mathrm{Ni}$ or their mixtures) [103] orphosphate/silicate mixtures ( $x \mathrm{LiFe}$ $\left.\mathrm{PO}_{4} \cdot(1-x) \mathrm{Li}_{2} \mathrm{FeSiO}_{4}\right)$ [104] have demonstrated incremented capacity in regular half-cell tests (usually delivering at least $200 \mathrm{mAh} \mathrm{g}^{-1}$ ), fluoride mixtures could be easily analyzed in this regard. For example the system $x \mathrm{LiFe}_{2} \mathrm{~F}_{6} \cdot(1-x) \mathrm{Li}_{3} \mathrm{FeF}_{6}$ has not been investigated so far, while the mixture could certainly represent a valid candidate as a cathodic material. 
Besides the more advanced concepts expressed hereby, some fundamental questions still remain to be answered for the iron fluoride hydrated phases in particular. It is noteworthy that since the detailed description of the $\mathrm{FeF}_{3}$ behavior by Badway, Doe and Yamakawa, no in-depth structural/mechanistical studies have appeared. Except for the Maier's group, who carefully assessed not only the synthesis procedure but also the electrochemical characteristics of both the HTB and pyrochlore systems, all other publications have been focused for the best part on the synthesis procedures and/or the effects of addition of various carbon additives. For example, it has been pointed out that in ionic liquid-based syntheses, the final fluoride products are influenced both by the initial reaction temperature and by the reaction medium (nature of the ionic liquid). So far, no study presents a careful and rationalized assessment of the dehydration products for other synthetic mediums or studies their influence on the final fluoride material. Moreover, as the same structure can exist with different hydrated/hydrolyzed states, the relation to water contentelectrochemical behavior has still to be elucidated.

Another valid concept is the study of the electrode preparation/optimisation instead of synthesis. Effects such as current collector influence, separator influence, electrolyte decomposition and slurry composition have found very limited and non-organized reports in the current literature.

Finally, we would like to stress again that probably no practical materials would see the light of day if a solution to the prelithiation issue or the exploration of Na-based derivatives is not extensively investigated.

Open Access This article is distributed under the terms of the Creative Commons Attribution License which permits any use, distribution, and reproduction in any medium, provided the original author(s) and the source are credited.

\section{References}

1. Agricolae, G.: Bermannus sive de re metallica (on the nature of metals, or minerals). Dover Publications NY (1986)

2. Tressaud, A.: Functionalized inorganic fluorides: synthesis, characterization \& properties of nanostructured solids. Wiley, New York (2010)

3. Louvain, N., Fakhry, A., Bonnet, P., El-Ghozzi, M., Guerin, K., Sougrati, M.-T., Jumas, J.-C., Willmann, P.: One-shot versus stepwise gas-solid synthesis of iron trifluoride: investigation of pure molecular $\mathrm{F}_{2}$ fluorination of chloride precursors. CrystEngComm 15, 3664-3671 (2013)

4. Fedorov, P.P., Luginina, A.A., Kuznetsov, S.V., Osiko, V.V.: Nanofluorides. J. Fluor. Chem. 132, 1012-1039 (2011)

5. Cabana, J., Monconduit, L., Larcher, D., Palacin, M.R.: Beyond intercalation-based Li-ion batteries: the state of the art and challenges of electrode materials reacting through conversion reactions. Adv. Mater. 22, E170-E192 (2010)

6. Poizot, P., Laruelle, S., Grugeon, S., Dupont, L., Tarascon, J.M.: Nano-sized transition-metal oxides as negative-electrode materials for lithium-ion batteries. Nature 407, 496-499 (2000)
7. Liang, C., Gao, M., Pan, H., Liu, Y., Yan, M.: Lithium alloys and metal oxides as high-capacity anode materials for lithiumion batteries. J. Alloys Compd. 575, 246-256 (2013)

8. Tarascon, J.M.: Key challenges in future Li-battery research. Phil. Trans. R. Soc. A 368, 3227-3241 (2010)

9. Bauman, H.F.: Limited-cycle secondary battery using lithium anode. In: center, D.D. (ed.). p. 29. Lockheed Missiles \& Space Company, Palo Alto (1964)

10. Bauman, H.F., Chiton, J.E., Mauri, R.: Lithium anode limited cycle battery investigation. In: center, D.d. (ed.). p. 81. Lockheed Missiles \& Space Company, Palo Alto (1966)

11. Bauman, H.F., Chilton, J.E., Hultquist, A.E., Adams, G.B.: Lithium anode limited cycle battery investigation. In: center, D.D. (ed.). p. 40. Lockheed Missiles \& Space Company, Palo Alto (1966)

12. Fiordiponti, P., Panero, S., Pistoia, G., Temperoni, C.: Nonaqueous batteries with $\mathrm{BiF}_{3}$ cathodes. J. Electrochem. Soc. 125, 511-515 (1978)

13. Guyomard, D., Tarascon, J.M.: Rocking-chair or lithium-ion rechargeable lithium batteries. Adv. Mater. 6, 408-412 (1994)

14. Whittingham, M.S.: Lithium batteries and cathode materials. Chem. Rev. 104, 4271-4301 (2004)

15. Arai, H., Okada, S., Sakurai, Y., Yamaki, J.: Cathode performance and voltage estimation of metal trihalides. J. Power Sources 68, 716-719 (1997)

16. Badway, F., Pereira, N., Cosandey, F., Amatucci, G.G.: Carbonmetal fluoride nanocomposites: structure and electrochemistry of $\mathrm{FeF}_{3}:$ C. J. Electrochem. Soc. 150, A1209-A1218 (2003)

17. Badway, F., Cosandey, F., Pereira, N., Amatucci, G.G.: Carbon metal fluoride nanocomposites: high-capacity reversible metal fluoride conversion materials as rechargeable positive electrodes for Li batteries. J. Electrochem. Soc. 150, A1318-A1327 (2003)

18. Cosandey, F., Al-Sharab, J.F., Badway, F., Amatucci, G.G., Stadelmann, P.: EELS spectroscopy of iron fluorides and $\mathrm{FeF}_{\mathrm{x}} / \mathrm{C}$ nanocomposite electrodes used in Li-ion batteries. Microsc. Microanal. 13, 87-95 (2007)

19. Doe, R.E., Persson, K.A., Meng, Y.S., Ceder, G.: First-principles investigation of the Li-Fe-F phase diagram and equilibrium and nonequilibrium conversion reactions of iron fluorides with lithium. Chem. Mater. 20, 5274-5283 (2008)

20. Yamakawa, N., Jiang, M., Key, B., Grey, C.P.: Identifying the local structures formed during lithiation of the conversion material, iron fluoride, in a $\mathrm{Li}$ ion battery: a solid-state NMR, X-ray diffraction, and pair distribution function analysis study. J. Am. Chem. Soc. 131, 10525-10536 (2009)

21. Tan, H.J., Smith, H.L., Kim, L., Harding, T.K., Jones, S.C., Fultz, B.: Electrochemical cycling and lithium Insertion in nanostructured $\mathrm{FeF}_{3}$ cathodes. J. Electrochem. Soc. 161, A445A449 (2014)

22. Liu, P., Vajo, J.J., Wan, J.S., Li, W., Liu, J.: Thermodynamics and kinetics of the $\mathrm{Li} / \mathrm{FeF}_{3}$ reaction by electrochemical analysis. J. Phys. Chem. C 116, 6467-6473 (2012)

23. Zhou, M.J., Zhao, L.W., Doi, T., Okada, S., Yamaki, J.: Thermal stability of $\mathrm{FeF}_{3}$ cathode for Li-ion batteries. J. Power Sources 195, 4952-4956 (2010)

24. Zhou, M.J., Zhao, L.W., Okada, S., Yamaki, J.: Thermal characteristics of $\mathrm{a} \mathrm{FeF}_{3}$ cathode via conversion reaction in comparison with $\mathrm{LiFePO}_{4}$. J. Power Sources 196, 8110-8115 (2011)

25. Zhou, M.J., Zhao, L.W., Kitajou, A., Okada, S., Yamaki, J.: Mechanism on exothermic heat of $\mathrm{FeF}_{3}$ cathode in Li-ion batteries. J. Power Sources 203, 103-108 (2012)

26. Brauer, G.: Handbook of preparative inorganic chemistry, vol. 1, 2 ed. Academic Press, NY (1963)

27. Wu, W., Wang, X., Wang, X., Yang, S., Liu, X., Chen, Q.: Effects of $\mathrm{MoS}_{2}$ doping on the electrochemical performance of $\mathrm{FeF}_{3}$ cathode materials for lithium-ion batteries. Mater. Lett. 63 , 1788-1790 (2009) 
28. Wu, W., Wang, Y., Wang, X., Chen, Q., Wang, X., Yang, S., Liu, X., Guo, J., Yang, Z.: Structure and electrochemical performance of $\mathrm{FeF}_{3} / \mathrm{V}_{2} \mathrm{O}_{5}$ composite cathode material for lithiumion battery. J. Alloys Compd. 486, 93-96 (2009)

29. Karraker, D.G., Smith, P.K.: Alpha- $\mathrm{FeF}_{3} * 3 \mathrm{H}_{2} \mathrm{O}$ and beta$\mathrm{FeF}_{3} * 3 \mathrm{H}_{2} \mathrm{O}$ revisited: crystal structure and $\mathrm{Fe}^{57}$ Mossbauer spectra. Inorg. Chem. 31, 1118-1120 (1992)

30. Li, C., Yin, C., Gu, L., Dinnebier, R.E., Mu, X., van Aken, P.A., Maier, J.: $\mathrm{An} \mathrm{FeF}_{3}{ }^{*} 0.5 \mathrm{H}_{2} \mathrm{O}$ polytype: a microporous framework compound with intersecting tunnels for $\mathrm{Li}$ and $\mathrm{Na}$ batteries. J. Am. Chem. Soc. 135, 11425-11428 (2013)

31. Demourgues, A., Francke, L., Durand, E., Tressaud, A.: Chemistry and key structural features of oxyhydroxy-fluorides: relationships with the acidic character, thermal stability and surface area. J. Fluor. Chem. 114, 229-236 (2002)

32. Francke, L., Durand, E., Demourgues, A., Vimont, A., Daturi, M., Tressaud, A.: Synthesis and characterization of $\mathrm{Al}^{3+}, \mathrm{Cr}^{3+}$, $\mathrm{Fe}^{3+}$ and $\mathrm{Ga}^{3+}$ hydroxyfluorides: correlations between structural features, thermal stability and acidic properties. J. Mater. Chem. 13, 2330-2340 (2003)

33. Vimont, A., Lavalley, J.C., Francke, L., Demourgues, A., Tressaud, A., Daturi, M.: Infrared study of the surface properties of HTB-type Al-, Cr-, Fe-hydroxyfluorides. J. Phys. Chem. B 108, 3246-3255 (2004)

34. Li, C.L., Gu, L., Tsukimoto, S., van Aken, P.A., Maier, J.: Lowtemperature ionic-liquid-based synthesis of nanostructured ironbased fluoride cathodes for lithium batteries. Adv. Mater. 22, $3650(2010)$

35. Li, C.L., Gu, L., Tong, J.W., Tsukimoto, S., Maier, J.: A mesoporous iron-based fluoride cathode of tunnel structure for rechargeable lithium batteries. Adv. Funct. Mater. 21, 1391-1397 (2011)

36. Li, C.L., Gu, L., Tong, J.W., Maier, J.: Carbon nanotube wiring of electrodes for high-rate lithium batteries using an imidazolium-based ionic liquid precursor as dispersant and binder: a case study on iron fluoride nanoparticles. ACS Nano 5, 2930-2938 (2011)

37. Li, C.L., Yin, C.L., Mu, X.K., Maier, J.: Top-down synthesis of open framework fluoride for lithium and sodium batteries. Chem. Mater. 25, 962-969 (2013)

38. Li, C.L., Mu, X.K., van Aken, P.A., Maier, J.: A high-capacity cathode for lithium batteries consisting of porous microspheres of highly amorphized iron fluoride densified from Its open parent phase. Adv. Energy Mater. 3, 113-119 (2013)

39. Li, B., Rooney, D.W., Zhang, N., Sun, K.: An in situ ionicliquid-assisted synthetic approach to iron fluoride/graphene hybrid nanostructures as superior cathode materials for lithium ion batteries. ACS Appl. Mater. Interfaces 5, 5057-5063 (2013)

40. Lu, Y., Wen, Z., Rui, K., Wu, X., Cui, Y.: Worm-like mesoporous structured iron-based fluoride: facile preparation and application as cathodes for rechargeable lithium ion batteries. J. Power Sources 244, 306-311 (2013)

41. Di Carlo, L., Conte, D.E., Kemnitz, E., Pinna, N.: Microwaveassisted fluorolytic sol-gel route to iron fluoride nanoparticles for Li-ion batteries. Chem. Commun. 50, 460-462 (2014)

42. Xu, X., Chen, S., Shui, M., Xu, L., Zheng, W., Shu, J., Cheng, L., Feng, L., Ren, Y.: One step solid state synthesis of $\mathrm{FeF}_{3} * 0.33 \mathrm{H}_{2} \mathrm{O} / \mathrm{C}$ nano-composite as cathode material for lithium-ion batteries. Ceram. Int. 40, 3145-3148 (2014)

43. Yang, Z.H., Pei, Y., Wang, X.Y., Liu, L., Su, X.P.: First principles study on the structural, magnetic and electronic properties of Co-doped $\mathrm{FeF}_{3}$. Comput. Theor. Chem. 980, 44-48 (2012)

44. Liu, L., Zhou, M., Yi, L., Guo, H., Tan, J., Shu, H., Yang, X., Yang, Z., Wang, X.: Excellent cycle performance of Co-doped $\mathrm{FeF}_{3} / \mathrm{C}$ nanocomposite cathode material for lithium-ion batteries. J. Mater. Chem. 22, 17539-17550 (2012)
45. Liu, L., Guo, H., Zhou, M., Wei, Q., Yang, Z., Shu, H., Yang, X., Tan, J., Yan, Z., Wang, X.: A comparison among $\mathrm{FeF}_{3} * 3 \mathrm{H}_{2} \mathrm{O}, \mathrm{FeF}_{3} * 0.33 \mathrm{H}_{2} \mathrm{O}$ and $\mathrm{FeF}_{3}$ cathode materials for lithium ion batteries: structural, electrochemical, and mechanism studies. J. Power Sources 238, 501-515 (2013)

46. Shi, Y.L., Wu, N., Shen, M.F., Cui, Y.L., Jiang, L., Qiang, Y.H., Zhuang, Q.C.: Electrochemical behavior of iron(III) fluoride trihydrate as a cathode in lithium-ion batteries. ChemElectroChem. doi:10.1002/celc.201300069 (2014, in press)

47. Li, L.S., Yu, Y.H., Meng, F., Tan, Y.Z., Hamers, R.J., Jin, S.: Facile solution synthesis of alpha- $\mathrm{FeF}_{3} * 3 \mathrm{H}_{2} \mathrm{O}$ nanowires and their conversion to alpha- $\mathrm{Fe}_{2} \mathrm{O}_{3}$ nanowires for photoelectrochemical application. Nano Lett. 12, 724-731 (2012)

48. Li, L., Meng, F., Jin, S.: High-capacity lithium-ion battery conversion cathodes based on iron fluoride nanowires and insights into the conversion mechanism. Nano Lett. 12, 6030-6037 (2012)

49. Morin, S.A., Bierman, M.J., Tong, J., Jin, S.: Mechanism and kinetics of spontaneous nanotube growth driven by screw dislocations. Science 328, 476-480 (2010)

50. Wang, F., Robert, R., Chernova, N.A., Pereira, N., Omenya, F., Badway, F., Hua, X., Ruotolo, M., Zhang, R.G., Wu, L.J., Volkov, V., Su, D., Key, B., Whittingharn, M.S., Grey, C.P., Amatucci, G.G., Zhu, Y.M., Graetz, J.: Conversion reaction mechanisms in lithium ion batteries: study of the binary metal fluoride electrodes. J. Am. Chem. Soc. 133, 18828-18836 (2011)

51. Chu, Q., Xing, Z., Tian, J., Ren, X., Asiri, A.M., Al-Youbi, A.O., Alamry, K.A., Sun, X.: Facile preparation of porous $\mathrm{FeF}_{3}$ nanospheres as cathode materials for rechargeable lithium-ion batteries. J. Power Sources 236, 188-191 (2013)

52. Chu, Q., Xing, Z., Ren, X., Asiri, A.M., Al-Youbi, A.O., Alamry, K.A., Sun, X.: Reduced graphene oxide decorated with $\mathrm{FeF}_{3}$ nanoparticles: Facile synthesis and application as a high capacity cathode material for rechargeable lithium batteries. Electrochim. Acta 111, 80-85 (2013)

53. Kim, S.W., Seo, D.H., Gwon, H., Kim, J., Kang, K.: Fabrication of $\mathrm{FeF}_{3}$ nanoflowers on $\mathrm{CNT}$ branches and their application to high power lithium rechargeable batteries. Adv. Mater. 22, 5260-5264 (2010)

54. Li, T., Li, L., Cao, Y.L., Ai, X.P., Yang, H.X.: Reversible threeelectron redox behaviors of $\mathrm{FeF}_{3}$ nanocrystals as high-capacity cathode-active materials for Li-ion batteries. J. Phys. Chem. C 114, 3190-3195 (2010)

55. Zaghib, K., Guerfi, A., Hovington, P., Vijh, A., Trudeau, M., Mauger, A., Goodenough, J.B., Julien, C.M.: Review and analysis of nanostructured olivine-based lithium recheargeable batteries: status and trends. J. Power Sources 232, 357-369 (2013)

56. Liu, J., Wan, Y., Liu, W., Ma, Z., Ji, S., Wang, J., Zhou, Y., Hodgson, P., Li, Y.: Mild and cost-effective synthesis of iron fluoride-graphene nanocomposites for high-rate Li-ion battery cathodes. J. Mater. Chem. A 1, 1969-1975 (2013)

57. Ma, R., Lu, Z., Wang, C., Wang, H.-E., Yang, S., Xi, L., Chung, J.C.Y.: Large-scale fabrication of graphene-wrapped $\mathrm{FeF}_{3}$ nanocrystals as cathode materials for lithium ion batteries. Nanoscale 5, 6338-6343 (2013)

58. Myung, S.T., Sakurada, S., Yashiro, H., Sun, Y.K.: Iron trifluoride synthesized via evaporation method and its application to rechargeable lithium batteries. J. Power Sources 223, 1-8 (2013)

59. Li, X., Liu, J., Meng, X., Tang, Y., Banis, M.N., Yang, J., Hu, Y., Li, R., Cai, M., Sun, X.: Significant impact on cathode performance of lithium-ion batteries by precisely controlled metal oxide nanocoatings via atomic layer deposition. J. Power Sources 247, 57-69 (2014) 
60. Zhang, W., Ma, L., Yue, H., Yang, Y.: Synthesis and characterization of in situ $\mathrm{Fe}_{2} \mathrm{O}_{3}$-coated $\mathrm{FeF}_{3}$ cathode materials for rechargeable lithium batteries. J. Mater. Chem. 22, 24769-24775 (2012)

61. Tiwari, J.N., Tiwari, R.N., Kim, K.S.: Zero-dimensional, onedimensional, two-dimensional and three-dimensional nanostructured materials for advanced electrochemical energy devices. Prog. Mater Sci. 57, 724-803 (2012)

62. Ma, D., Cao, Z., Wang, H., Huang, X., Wang, L., Zhang, X.: Three-dimensionally ordered macroporous $\mathrm{FeF}_{3}$ and its in situ homogenous polymerization coating for high energy and power density lithium ion batteries. Energy Environ. Sci. 5, 8538-8542 (2012)

63. Jung, H., Shin, J., Chae, C., Lee, J.K., Kim, J.: FeF $F_{3}$ Ordered Mesoporous Carbon (OMC) nanocomposites for lithium ion batteries with enhanced electrochemical performance. J. Phys. Chem. C 117, 14939-14946 (2013)

64. Liu, L., Zhou, M., Wang, X.Y., Yang, Z.H., Tian, F.H.: Synthesis and electrochemical performance of spherical $\mathrm{FeF}_{3} /$ ACMB composite as cathode material for lithium-ion batteries. J. Mater. Sci. 47, 1819-1824 (2012)

65. Tan, J., Liu, L., Hu, H., Yang, Z., Guo, H., Wei, Q., Yi, X., Yan, Z., Zhou, Q., Huang, Z., Shu, H., Yang, X., Wang, X.: Iron fluoride with excellent cycle performance synthesized by solvothermal method as cathodes for lithium ion batteries. J. Power Sources 251, 75-84 (2014)

66. Martha, S.K., Nanda, J., Zhou, H., Idrobo, J.C., Dudney, N.J., Pannala, S., Dai, S., Wang, J., Braun, P.V.: Electrode architectures for high capacity multivalent conversion compounds: iron (II and III) fluoride. Rsc Adv. 4, 6730-6737 (2014)

67. Oudenhoven, J.F.M., Baggetto, L., Notten, P.H.L.: All-solidstate lithium-ion microbatteries: a review of various threedimensional concepts. Adv. Energy Mater. 1, 10-33 (2011)

68. Knoops, H.C.M., Donders, M.E., van de Sanden, M.C.M., Notten, P.H.L., Kessels, W.M.M.: Atomic layer deposition for nanostructured Li-ion batteries. J. Vac. Sci. Technol. A 30 (2012)

69. Makimura, Y., Rougier, A., Tarascon, J.M.: Pulsed laser deposited iron fluoride thin films for lithium-ion batteries. Appl. Surf. Sci. 252, 4587-4592 (2006)

70. Makimura, Y., Rougier, A., Laffont, L., Womes, M., Jumas, J.C., Leriche, J.B., Tarascon, J.M.: Electrochemical behaviour of low temperature grown iron fluoride thin films. Electrochem. Commun. 8, 1769-1774 (2006)

71. Guitian, B., Lascaud, S., Novoa, X.R., Ribeaucourt, L., Vidal, E.: On the growth of nanostructured iron hydroxy-fluorides for Li-ion batteries. J. Power Sources 241, 567-571 (2013)

72. Pereira, N., Badway, F., Wartelsky, M., Gunn, S., Amatucci, G.G.: Iron oxyfluorides as high capacity cathode materials for lithium batteries. J. Electrochem. Soc. 156, A407-A416 (2009)

73. Li, Z., Huang, J., Liaw, B.Y., Metzler, V., Zhang, J.: A review of lithium deposition in lithium-ion and lithium metal secondary batteries. J. Power Sources 254, 168-182 (2014)

74. Portier, J., Tressaud, A., Depape, R., Hagenmuller, P.: Crystallography and magnetic study of an unpublished fluoride of trirutile type. C. R. Acad. Sc. Ser. C 267, 1711-1713 (1968)

75. Fourquet, J.L., Lesamedi, E., Calage, Y.: Crystal growth and crystal structure of trirutile $\mathrm{LiFe}_{2} \mathrm{~F}_{6}$. J. Solid State Chem. 77, 84-89 (1988)

76. Liao, P., Li, J., Dahn, J.R.: Lithium intercalation in $\mathrm{LiFe}_{2} \mathrm{~F}_{6}$ and $\mathrm{LiMgFeF}_{6}$ disordered trirutile-type phases. J. Electrochem. Soc. 157, A355-A361 (2010)

77. Liao, P., Dunlap, R.A., Dahn, J.R.: In situ Mossbauer effect study of lithium intercalation in $\mathrm{LiFe}_{2} \mathrm{~F}_{6}$. J. Electrochem. Soc. 157, A1080-A1084 (2010)
78. Amatucci, G.G.: Electrode composition useful as positive electrode material of electrochemical cell e.g. lithium battery cell, comprises lithium fluoride compound demonstrating high specific capacity. WO2004051772-A2; US2004121235-A1; AU2003295927-A1; AU2003295927-A8; US7371338-B2; WO2004051772-A3

79. Amatucci, G.G., Pereira, N., Badway, F., Sina, M., Cosandey, F., Ruotolo, M., Cao, C.: Formation of lithium fluoride/metal nanocomposites for energy storage through solid state reduction of metal fluorides. J. Fluor. Chem. 132, 1086-1094 (2011)

80. Liao, P., MacDonald, B.L., Dunlap, R.A., Dahn, J.R.: Combinatorially prepared $[\mathrm{LiF}]_{1-\mathrm{x}} \mathrm{Fe}_{\mathrm{x}}$ nanocomposites for positive electrode materials in Li-ion batteries. Chem. Mater. 20, 454-461 (2008)

81. Liao, P., Dunlap, R.A., Dahn, J.R.: A Mossbauer effect study of combinatorially prepared $\mathrm{Al}_{2} \mathrm{O}_{3} / \mathrm{Fe}$ and $\mathrm{LiF} / \mathrm{Fe}$ multilayers. J. Phys.: Condens. Matter 20, 055203 (2008)

82. Li, T., Chen, Z.X., Ai, X.R., Cao, Y.L., Yang, H.X.: LiF/Fe nanocomposite as a lithium-rich and high capacity conversion cathode material for Li-ion batteries. J. Power Sources 217, 54-58 (2012)

83. Kim, S.W., Nam, K.W., Seo, D.H., Hong, J., Kim, H., Gwon, H., Kang, K.: Energy storage in composites of a redox couple host and a lithium ion host. Nano Today 7, 168-173 (2012)

84. Ma, R., Dong, Y., Xi, L., Yang, S., Lu, Z., Chung, C.: Fabrication of $\mathrm{LiF} / \mathrm{Fe} /$ graphene nanocomposites as cathode material for lithium-ion batteries. ACS Appl. Mater. Interfaces 5, 892-897 (2013)

85. Prosini, P.P., Masci, A., Cento, C., Gislon, P.: A composite electrode based on sub-micrometric iron metal and lithium fluoride. Electrochim. Acta 106, 312-319 (2013)

86. Prakash, R., Mishra, A.K., Roth, A., Kuebel, C., Scherer, T., Ghafari, M., Hahn, H., Fichtner, M.: A ferrocene-based carboniron lithium fluoride nanocomposite as a stable electrode material in lithium batteries. J. Mater. Chem. 20, 1871-1876 (2010)

87. Prakash, R., Wall, C., Mishra, A.K., Kuebel, C., Ghafari, M., Hahn, H., Fichtner, M.: Modified synthesis of $[\mathrm{Fe} / \mathrm{LiF} / \mathrm{C}]$ nanocomposite, and its application as conversion cathode material in lithium batteries. J. Power Sources 196, 5936-5944 (2011)

88. Zhang, S., Lu, Y., Xu, G., Li, Y., Zhang, X.: LiF/Fe/C nanofibres as a high-capacity cathode material for Li-ion batteries. J. Phys. D Appl. Phys. 45, 395301-395307 (2012)

89. Gonzalo, E., Kuhn, A., Garcia-Alvarado, F.: On the room temperature synthesis of monoclinic $\mathrm{Li}_{3} \mathrm{FeF}_{6}$ : a new cathode material for rechargeable lithium batteries. J. Power Sources 195, 4990-4996 (2010)

90. Gonzalo, E., Kuhn, A., Garcia-Alvarado, F.: A comparative study of alpha- and beta- $\mathrm{Li}_{3} \mathrm{FeF}_{6}$ : structure and electrochemical behavior. J. Electrochem. Soc. 157, A1002-A1006 (2010)

91. Basa, A., Gonzalo, E., Kuhn, A., Garcia-Alvarado, F.: Reaching the full capacity of the electrode material $\mathrm{Li}_{3} \mathrm{FeF}_{6}$ by decreasing the particle size to nanoscale. J. Power Sources 197, 260-266 (2012)

92. Gonzalo, E., Kuhn, A., Garcia-Alvarado, F., Islam, M.S.: Defect and dopant properties of the alpha- and beta-polymorphs of the $\mathrm{Li}_{3} \mathrm{FeF}_{6}$ lithium battery material. J. Mater. Chem. A 1, 6588-6592 (2013)

93. Schroeder, M., Eames, C., Tompsett, D.A., Lieser, G., Islam, M.S.: $\mathrm{Li}_{\mathrm{x}} \mathrm{FeF}_{6}(\mathrm{x}=2,3,4)$ battery materials: structural, electronic and lithium diffusion properties. Phys. Chem. Chem. Phys. 15, 20473-20479 (2013)

94. Palomares, V., Casas-Cabanas, M., Castillo-Martinez, E., Han, M.H., Rojo, T.: Update on Na-based battery materials. A 
growing research path. Energy Environ. Sci. 6, 2312-2337 (2013)

95. Nishijima, M., Gocheva, I.D., Okada, S., Doi, T., Yamaki, J.-I., Nishida, T.: Cathode properties of metal trifluorides in $\mathrm{Li}$ and Na secondary batteries. J. Power Sources 190, 558-562 (2009)

96. Gocheva, I.D., Nishijima, M., Doi, T., Okada, S., Yamaki, J.-I., Nishida, T.: Mechanochemical synthesis of $\mathrm{NaMF}_{3}(\mathrm{M}=\mathrm{Fe}$, $\mathrm{Mn}, \mathrm{Ni}$ ) and their electrochemical properties as positive electrode materials for sodium batteries. J. Power Sources 187, 247-252 (2009)

97. Kitajou, A., Komatsu, H., Chihara, K., Gocheva, I.D., Okada, S.: Yamaki, J.-i.: Novel synthesis and electrochemical properties of perovskite-type $\mathrm{NaFeF}_{3}$ for a sodium-ion battery. J. Power Sources 198, 389-392 (2012)

98. Dimov, N., Nishimura, A., Chihara, K., Kitajou, A., Gocheva, I.D., Okada, S.: Transition metal $\mathrm{NaMF}_{3}$ compounds as model systems for studying the feasibility of ternary Li-M-F and Na$\mathrm{M}-\mathrm{F}$ single phases as cathodes for lithium-ion and sodium-ion batteries. Electrochim. Acta 110, 214-220 (2013)

99. Yamada, Y., Doi, T., Tanaka, I., Okada, S.: Yamaki, J.-i.: Liquid-phase synthesis of highly dispersed $\mathrm{NaFeF}_{3}$ particles and their electrochemical properties for sodium-ion batteries. J. Power Sources 196, 4837-4841 (2011)

100. Shakoor, R.A., Lim, S.Y., Kim, H., Nam, K.-W., Kang, J.K., Kang, K., Choi, J.W.: Mechanochemical synthesis and electrochemical behavior of $\mathrm{Na}_{3} \mathrm{FeF}_{6}$ in sodium and lithium batteries. Solid State Ionics 218, 35-40 (2012)

101. Manthiram, A., Goodenough, J.B.: Lithium insertion into $\mathrm{Fe}_{2}\left(\mathrm{SO}_{4}\right)_{3}$ frameworks. J. Power Sources 26, 403-408 (1989)

102. Melot, B.C., Tarascon, J.M.: Design and preparation of materials for advanced electrochemical storage. Acc. Chem. Res. 46, 1226-1238 (2013)

103. Wu, F., Li, N., Su, Y., Shou, H., Bao, L., Yang, W., Zhang, L., An, R., Chen, S.: Spinel/layered heterostructured cathode material for high-capacity and high-rate Li-ion batteries. Adv. Mater. 25, 3722-3726 (2013)

104. Gao, H., Hu, Z., Zhang, K., Cheng, F., Chen, J.: Intergrown $\mathrm{Li}_{2} \mathrm{FeSiO}_{4} * \mathrm{LiFePO}_{4}-\mathrm{C}$ nanocomposites as high-capacity cathode materials for lithium-ion batteries. Chem. Commun. 49, 3040-3042 (2013) 